\title{
Heat and Mass Transfer During Fry-Drying of Sewage Sludge
}

\author{
C. Peregrina, ${ }^{1}$ P. Arlabosse, ${ }^{1}$ D. Lecomte, ${ }^{1}$ and V. Rudolph ${ }^{2}$ \\ ${ }^{1}$ Laboratoire de Génie de Procédés des Solides Divisés (UMR 2392), Ecole des Mines d'Albi \\ Carmaux, Albi, France \\ ${ }^{2}$ Department of Chemical Engineering, University of Queensland, St Lucia, Australia
}

Deep frying, which consists of immersing a wet material in a large volume of hot oil, presents a process easily adaptable to dry rather than cook materials. A suitable material for drying is sewage sludge, which may be dried using recycled cooking oils (RCO) as frying oil. One advantage is that this prepares both materials for convenient disposal by incineration.

This study examines fry drying of municipal sewage sludge using recycled cooking oil. The transport processes occurring during fry drying were monitored through sample weight, temperature, and image analysis. Due to the thicker and wetter samples than the common fried foods, high residual moisture is observed in the sludge when the boiling front has reached the geometric center of the sample, suggesting that the operation is heat transfer controlled only during the first half of the process followed by the addition of other mechanisms that allow complete drying of the sample. A series of mechanisms comprising four stages (i.e., initial heating accompanied by a surface boiling onset, film vapor regime, transitional nucleate boiling, and bound water removal) is proposed In order to study the effect of the operating conditions on the fry drying kinetics, different oil temperatures (from 120 to $180^{\circ} \mathrm{C}$ ), diameter ( $D \quad 15$ to $25 \mathrm{~mm}$ ), and initial moisture content of the sample (4.8 and $5.6 \mathrm{~kg}$ water $\cdot \mathrm{kg}^{-1}$ total dry solids) were investigated.

Keywords Boiling; Drying; Frying; Incineration; Impregnation; Recycled cooking oil

\section{INTRODUCTION}

Deep-frying, which consists of immersing a wet material in a large volume of hot oil, is a multifunctional unit operation for drying, formulating, and texturing the material. ${ }^{[1]}$ It is commonly used in the food industry, but innovative applications have been suggested for non-food materials, like timber or sewage sludge. ${ }^{[2]}$

Sewage sludge is a by-product of wastewater treatment and represents a significant problem in terms of its volume $(850,000 \text { tons of dry matter per year in France in } 1998)^{[3]}$

Correspondence: D. Lecomte, Laboratoire de Génie de Pro cédés des Solides Divisés (UMR 2392), Ecole des Mines d'Albi Carmaux, Route de Teillet, 81013 Albi CT Cedex 09, France; E mail: lecomte@enstimac.fr and of its organic content, especially regarding final disposal. Sewage sludge is commonly land spread as complementary fertilizer in agriculture, used as a co-fuel, or disposed of in landfills. Whatever the chosen disposal route, drying is often included as a stage in sludge treatment. ${ }^{[3-7]}$ In fact, thermal drying allows the removal of the moisture contained in the sludge after mechanical dewatering to $4 \mathrm{~kg}$ water $\cdot \mathrm{kg}^{-1}$ dry matter. This results in reduction in its volume and increase in the calorific value. Moreover, further drying allows stabilization of the sludge and, if the residence time and the temperature are sufficient, to make the product hygienic.

Most sludge dryers are evolved from standard process drying, but adaptation of existing technologies is not straightforward owing to the unusual stickiness of sludge ${ }^{[8,9]}$ (for indirect dryers) or to the unpleasant odors and risk of explosion ${ }^{[6]}$ (for direct dryers). Immersion frying constitutes an alternative process to thermal drying of sewage sludge. A first feasibility study, performed with municipal sewage sludge and peanut oil, showed that using a fry-drying process, a very low moisture content is reached in a few minutes and that oil is adsorbed on the dry solid. ${ }^{[10]}$ The final fry-dried sludge is easily handled and has a higher calorific value than the sludge conventionally air-dried. In order to reduce the economic impact of the process, further studies proposed the use of recycled cooking oil (RCO) as frying oil ${ }^{[11]}$ and the results showed no sensible modification to the drying kinetics. ${ }^{[12]}$ The RCO is a generic name for the oily phase resulting after several stages of purification of waste vegetable oils and greasy wastewater collected in the grease traps of restaurants, agricultural, and food industries outlets. ${ }^{[13]}$ Finding new ways of disposing of RCO has become a major concern for the European food industry since their use as an animal-feed ingredient was prohibited few years ago. ${ }^{[13]}$ Animal feed previously accounted for $85 \%$ of the oil collected in France. ${ }^{[14]}$ Consequently, new methods for the economic disposal of RCO are required. Co-valorization of RCO and sewage sludge to formulate a derived fuel provides such an opportunity. 
As immersion frying is an old, well-established, and widely used operation, little attention was paid to the understanding of the frying process mechanisms for quite a long time. With process and product optimization requirements, some research activity, driven by the food industries, occurred in the mid-1970s. As a result, the heat, mass, and momentum transfer mechanisms are partially understood. ${ }^{[2,15-21]}$ The experiments performed essentially with food materials revealed that, after immersion into the heated oil and initial heating of the raw material by convection, a dried crust begins to form at the product's surface. Its thickness increases over the duration of the frying process until the core region is dried. The heat is supplied by convection to the outer surface of the material and by conduction through the solid material to the core region. As a result, water is vaporized at the crust/core interface and flows to the outer surface. In addition to these transport mechanisms, physicochemical reactions occur, namely, oil sorption, microbial destruction, and Maillard reactions. ${ }^{[22-27]}$ Much more recently, frying has been recognized as a potential unit operation for drying that can be applied in a variety of industrial processes. ${ }^{[1]}$

The aim of this article is to present and analyze the experimental results when applying deep-fat frying to the thermal drying of sewage sludge using RCO as frying oil. One focus is to provide qualitative descriptions of the mechanisms involved; another is to quantify the effect of the main operational conditions on the fry-drying kinetics. Further, the aim is to identify similarities and differences between fry-drying for industrial applications and food cooking applications and also offer a basis for further developments of this technology such as scale-up and modeling of the fry-drying process.

\section{MATERIALS}

\section{Sewage Sludge Samples}

The study was performed with the municipal sewage sludge coming from the wastewater treatment plant (WWTP) of Albi (France). In that WWTP, a primary sedimentation is carried out followed by a biological secondary treatment. The primary and the activated sludges are mixed and sent to a mesophilic anaerobic digester ${ }^{1}$ where a fraction of the organic matter is decomposed into biogas. The sludge is thus stabilized to reduce pathogens, eliminate offensive odors, and lower the potential for putrefaction. Finally, the digested sludge is mechanically dewatered with

${ }^{1}$ Currently, anaerobic digestion is not the most widely prac ticed treatment for sludge in France. However, since 1998, new policies regarding the practices of land spreading and landfill of sewage sludge, combined with recent technological progress in biogas production and valorization (in particular in northern Europe and the United States) give new impetus to these processes in the French context. ${ }^{[28]}$
TABLE 1

Proximate and ultimate analysis of sewage sludge from the WWTP of Albi (France) and the RCO from Sud-Recuperation (Muret, France)

\begin{tabular}{lcc}
\hline Composition & $\begin{array}{c}\text { Sewage } \\
\text { sludge }\end{array}$ & $\begin{array}{c}\text { Recycled cooking } \\
\text { oils (RCO) }\end{array}$ \\
\hline [TS] (\%) & $19 \pm 3$ & $97 \pm 3$ \\
[TVS] (\% TS) & $33 \pm 3$ & $0.6 \pm 0.6$ \\
[TFS] (\%TS) & $67 \pm 3$ & $99.4 \pm 0.6$ \\
[C] (\%TS) & $36.4 \pm 3$ & $77.4 \pm 0.4$ \\
[H] (\%TS) & $5.5 \pm 0.2$ & $12.3 \pm 0.3$ \\
[O] (\%TS) & $18.8 \pm 1.5$ & $10.2 \pm 0.7$ \\
[N] (\%TS) & $5.7 \pm 0.2$ & $0.2 \pm 0.2$ \\
[S] (\%TS) & $1.0 \pm 0.1$ & $<0.01$ \\
\hline
\end{tabular}

a belt filter press to obtain a pasty sludge with a final moisture content between 4.0 and $6.0 \mathrm{~kg}$ water $\cdot \mathrm{kg}^{-1}$ total dry solids.

From a macroscopic point of view, ${ }^{[28]}$ the composition of the sludge is provided by the proximate ${ }^{2}$ and ultimate $^{3}$ analyses (see Table 1). For process design and management issues, the sludge is representative of the wastewater sludges produced in France. ${ }^{[29]}$ Furthermore, the micropollutants content of the Albi WWTP are close to average values provided by Huyard et al. ${ }^{[30]}$ from more than 500 French WWTP sludge samples (see Table 2).

For the fry-drying tests, the sludge is extruded in 145-mm-length cylindrical samples with diameters ranging from 15 to $25 \mathrm{~mm}$, using an adapted hand pusher (Reber, France). The density of each cylinder (since the volume is known and the mass easily measured) is used to verify the consistency of the various samples. A metallic grid holds the product and enables the placement of a series of $0.3 \mathrm{~mm}$ thick calibrated T-type micro-thermocouples (model 0059IM04, Teleph, France) in the sample (see Fig. 1) to monitor the sample temperature profile during the experiment.

\section{Recycled Cooking Oil}

The recycled cooking oil ( $\mathrm{RCO}$ ) used in this study is supplied by Sud Recuperation, a cooking oil recycler located in Muret (France) that collect the greasy wastewaters coming from fast food restaurant grease traps. On average, greasy wastewaters are composed of about $65 \%$

${ }^{2}$ Proximate analysis is a thermal gravimetric analysis that describes the total solids content (TS), total volatile solids content (TVS), and total fixed solids content (TFS) in a sample. TS con stitutes the remaining residue after drying of the wet sample at $105^{\circ} \mathrm{C}$, TVS those solids that can be volatilized and burned off when TS are ignited at $550^{\circ} \mathrm{C}$, and TFS is the residue that remains after ignition.

${ }^{3}$ The ultimate analysis gives the elemental $(\mathrm{C}, \mathrm{H}, \mathrm{O}, \mathrm{N}, \mathrm{S})$ compositions of the total solids matter. 
TABLE 2

Comparison of the micro-pollutant contents of the sewage sludge from the WWTP in Albi and those of the French average municipal sewage sludge ${ }^{[30]}$

\begin{tabular}{lcc}
\hline & $\begin{array}{c}\text { Sewage sludge } \\
\text { from the WWTP } \\
\text { in Albi (mg } \mathrm{kg}^{-1} \\
\text { total solids) }\end{array}$ & $\begin{array}{c}\text { Average French } \\
\text { sewage sludge } \\
\left(\mathrm{mg} \cdot \mathrm{kg}^{-1}\right. \\
\text { total solids })\end{array}$ \\
\hline $\begin{array}{l}\text { 7 Polychlorinated } \\
\text { biphenyls (PCBs) }\end{array}$ & 0.10 & 0.19 \\
Fluoranthene & 0.49 & 0.54 \\
Benzo(b)fluoranthene & 0.23 & 0.34 \\
Benzo(a)pyrene & 0.18 & 0.32 \\
$\mathrm{Cd}$ & 2.2 & $<3$ \\
$\mathrm{Cr}$ & 53.3 & 65.9 \\
$\mathrm{Cu}$ & 730 & 299.3 \\
$\mathrm{Hg}$ & 1.46 & 2.3 \\
$\mathrm{Ni}$ & 22.22 & 29.4 \\
$\mathrm{~Pb}$ & 145.6 & 94 \\
$\mathrm{Zn}$ & 980.2 & 773.3 \\
\hline
\end{tabular}

water and $35 \%$ other materials, $50 \%$ of which is fat. ${ }^{[14]}$ The $\mathrm{RCO}$ is separated from that mixture by a process comprising heating, decantation, and filtration. ${ }^{[31]}$ Results of the $\mathrm{RCO}$ ultimate and proximate analyses are presented in Table 1. Before their first use for fry-drying tests, the $\mathrm{RCO}$ is preheated for $1 \mathrm{~h}$ at $180^{\circ} \mathrm{C}$ to eliminate the remaining water.

The transport properties of the oil are likely to also have an important influence on the process. ${ }^{[32,33]}$ Since the RCO is recovered from a waste stream, some degree of thermal degradation, as a result of its previous use, may be expected. ${ }^{[24,34]}$ For the fry-drying process, the convective heat transfer coefficient $(h)$ between the product surface and the frying oil is important and is known ${ }^{[33]}$ to decrease with the degree of degradation. Viscosity, which increases with oil degradation, ${ }^{[32]}$ may be used as a convenient proxy to determine the extent of the change. Tseng et al. ${ }^{[33]}$ measured experimentally how $h$ and viscosity changed for degraded oils and showed that the two properties were highly correlated $(\mathrm{R}=-0.98)$. Using that correlation and

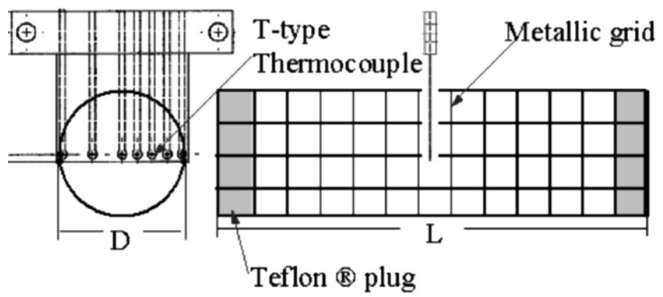

FIG. 1. Details of the sample container and micro-thermocouples.
TABLE 3

Effect of the oil degradation on their viscosity and the convective heat transfer coefficient according to Tseng et al. ${ }^{[33]}$

\begin{tabular}{lcc}
\hline Oil & $\begin{array}{c}\text { Viscosity } \\
(\mathrm{Pa} \cdot \mathrm{s}) \text { at } 190^{\circ} \mathrm{C}\end{array}$ & $\begin{array}{l}h\left(\mathrm{Wm}^{-2} \mathrm{~K}^{-1}\right) \\
\text { at } 190^{\circ} \mathrm{C}\end{array}$ \\
\hline Refined soybean oil & $2.04 \times 10^{-3}$ & 279.4 \\
20 h Degraded & $2.17 \times 10^{-3}$ & 276.2 \\
$\quad$ soybean oil & & \\
RCO & $2.46 \times 10^{-3}$ & $271.6^{*}$ \\
30 h Degraded & $2.57 \times 10^{-3}$ & 269.8 \\
$\quad$ soybean oil & & \\
\hline
\end{tabular}

${ }^{*}$ Calculated according to Tsen et al. ${ }^{[33]}$

the measured viscosity of the RCO used here, the expected values of $\mathrm{h}$ (Table 3 ) are quite similar to those of fresh oil, even though the RCO is quite degraded.

\section{Experimental Setup}

Continuous versus Discontinuous Measurement Methods

Most frying heat and mass transfer studies use a discontinuous method to construct the fry-drying curve. ${ }^{[17,18,35-37]}$ This requires interrupting frying experiments at various times and determining the moisture content of the sample by a destructive test. The main advantage of this method is that a moisture-time curve can be directly constructed. However, this method is time consuming and tedious, so that when the method is used, the drying curve is often built up from very few experimental points. ${ }^{[38]}$ Moreover, special attention is required for sample quenching after its removal from the frying bath, especially early in the drying process when the moisture content is high and water evaporation rate is intense. This practical difficulty in experiments leads to overestimation of the actual drying rate curve, particularly in the initial drying phase. ${ }^{[17,18,35-37]}$

The alternative method, which is performed by an on-line weighing of the system formed by the fryer, the oil bath, and the sample itself, provides a dynamic measure of the moisture loss due to water evaporation. Although this is rarely used in the frying study on foods, it was considered preferable for this work because of the high initial moisture content of the sludge and the problems related to its storage and aging. Moreover, the continuous measurement produces a larger number of experimental points to construct the moisture-time curve.

One natural difficulty of this method is the random noise in the measurement due to the vibrations of the sample ${ }^{[38]}$ however, for the fry-drying tests, the disturbances that may be caused by the stirring and/or the water boiling throughout the test are slight and overwhelmed within the accuracy of the measurements (i.e., $\pm 0.2 \mathrm{~g}$ ). Nevertheless, the determination of the sludge drying curve from the mass 
loss of the fryer, with the sample immersed in the oil bath, is not as straightforward as it may be for air-drying studies, for instance. The major difficulty concerns the mass balance between the recorded weight loss of the system and the actual water losses observed in the product. In fact, Kemp et al. ${ }^{[38]}$ explain that for most of the drying studies using the continuous weighing, the mass loss of the sample is directly recorded and assumed to represent the water loss of the product. Nevertheless, for the very few fry-drying works where this was applied, it was observed that some water did not leave the frying bath as vapor and remained somewhere in the fryer, probably as liquid water. ${ }^{[39]}$ As a consequence, in order to construct the actual fry-drying curve, the monitored mass loss must be adjusted with the liquid water losses. The implemented strategy to calculate the continuous drying curve of the sample will be described in Determination of Fry-Drying Curves.

\section{Experimental Setup}

The core of the experimental setup is a Model Pro 500 household deep-fat fryer (Magimix, Vincennes, France) with a maximum capacity of $5 \mathrm{~L}$. The fryer is heated with a 2000-W electrical resistance element, located near the bottom of the tank. The original thermostat control is inadequate for experimental purposes so it was replaced with a PID controller (Chromalox ${ }^{\circledR}$, Etrex SA, France).

A constant-speed stirrer (model: RW20DZM, IKAWerke GmbH \& Co., Staufen, Germany) operating at $50 \mathrm{rpm}$ provides mixing in the oil bath, using a propeller (R1330, IKA-Werke GmbH \& Co., Staufen, Germany) and also a turbine $(D=50.8 \mathrm{~mm}$, Cole-Parmer Instrument Company, Vernon Hills, Illinois, USA) fixed on a vertical shaft at the bottom and the middle of the tank, respectively. The stirrer homogenizes the oil temperature through the whole bath, without aeration or excessive turbulence. Temperature measurement is done by three calibrated K-type thermocouples immersed at different depths in the frying bath. One of these is used as the signal to the PID temperature controller. Four conventional frying temperatures, namely $120,140,160$, and $180^{\circ} \mathrm{C}$, have been investigated.

The experimental setup also includes a pneumatic jack (adjustable speed, $P_{\max }=10$ bar, ISOLLAIR, AxoJoucomatic, Rueil-Malmaison, France) to lower and raise the sludge so that the sample is immersed in the oil bath when the jack is lowered, and is removed and firmly secured when the jack is raised (see Fig. 2). In the lowered position, the metallic support, to which the sludge sample is hung, is set on the fryer walls (see Fig. 2, right). As a result, the mass loss due to water removal from the fryer could be continuously recorded using an electronic scale (max. load $32 \mathrm{~kg}$, accuracy $\pm 0.2 \mathrm{~g}$; model: IC34000P, Sartorius, Goettingen, Germany) placed under the deep-fat fryer. Mass is recorded every second by a data logger

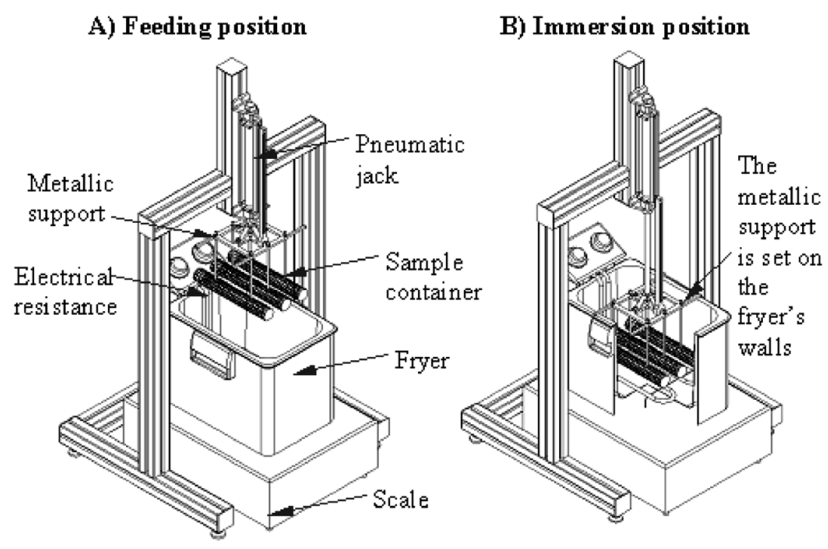

FIG. 2. Details of the experimental setup.

(Labview ${ }^{\circledR}$ 5.1, National Instruments, Austin, Texas, USA). The metallic support, to which the sample is hung, has been designed so that its weight is heavy enough to keep the sample immersed in the bath and avoid negative effects on mass measurements due to Archimedes forces.

All temperatures (i.e., in the sludge sample and frying oil) are recorded every second by a data logger ( $\mu$-MUSYCS ${ }^{\circledR}$, Imc Mes-System GmbH, Berlin, Germany).

\section{METHODS}

\section{Determination of Fry-Drying Curves}

The implemented strategy to compute the continuous fry-drying curve from the mass loss of the fryer consists of adjusting this curve to the reference drying curve provided by the discontinuous method.

\section{Moisture Content}

Moisture content denotes the quantity of water per unit of mass of either wet or dry product. For most of the drying and dewatering applications, the composition of a sludge is usually described according to the volatility of its components. ${ }^{[40]}$ Thus, from a macroscopic point of view, the composition is often presented as water mass $\left(m_{W}\right)$, which is the removed matter after drying of the wet sample at $105^{\circ} \mathrm{C}$ for $24 \mathrm{~h}$ and total dry solids mass $\left(m_{\mathrm{TS}}\right)$, which is the remaining matter. Consequently, the moisture content wet basis is defined as:

$$
\xi_{W}(\text { w.b. })=\frac{m_{W}}{m_{W}+m_{\mathrm{TS}}}
$$

and the moisture content dry basis as:

$$
\xi_{W}(\text { d.b. })=\frac{m_{W}}{m_{\mathrm{TS}}}
$$

However, during frying, water evaporation comes along with oil uptake on the solid. As a result, a sample of partially fry-dried sludge, at a fry-drying time $t=i$, will have 


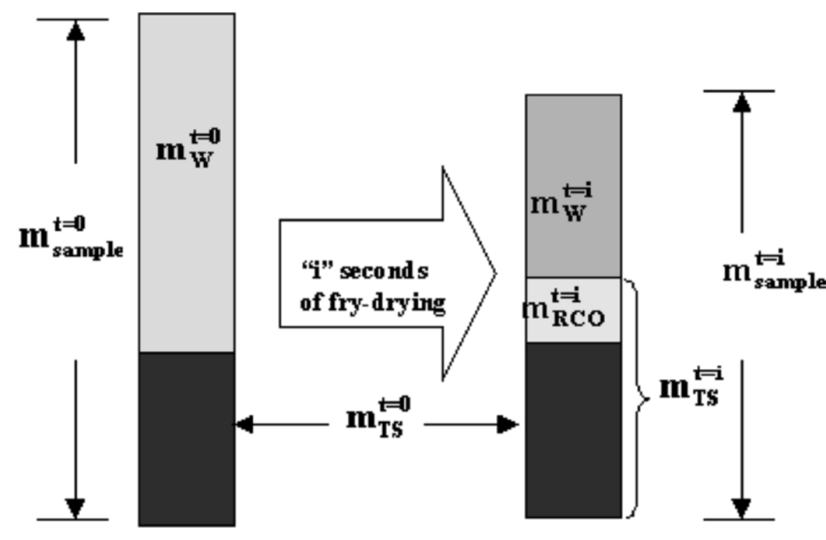

FIG. 3. Schematic representation of the mass composition change from dewatered to fry-dried sludge.

a mass $m_{\text {sample }}^{t i}$ including the mass of the moisture $m_{W}^{t}{ }^{i}$ and that of the total dry solids $m_{\mathrm{TS}}^{t}{ }^{i}$. This latter is the sum of the mass of the initial indigenous total dry solids $m_{\mathrm{TS}}^{t}{ }^{0}$ and that of the impregnated RCO $m_{\mathrm{RCO}}^{t} i$ as schematized in Fig. 3. In order to determine the degree of drying, the moisture content of the sample must be referenced solely to the indigenous total dry solids of the dewatered sludge. Consequently, it is necessary to differentiate the mass corresponding to each fraction of the total dry solids in the sample by determining $m_{\mathrm{RCO}}^{t}$. Unfortunately, some popular methods for oil content determination in fried foods, such as solvent extraction $^{[20]}$ and differential scanning calorimetry ${ }^{[41]}$ were not suitable when applied to the fry-dried samples in this study. Hence, in this article, $m_{\mathrm{RCO}}^{t} i$ is calculated by assuming that the indigenous total solids are insignificantly soluble in the frying oil and are not volatilized at the fry-drying temperatures. Thus, from the mass balance in the product,

$$
m_{\mathrm{RCO}}^{t i}=m_{\text {sample }}^{t i}-m_{W}^{t}{ }^{i}-m_{\mathrm{TS}}^{t}{ }^{0}
$$

Consequently, moisture content $\xi_{W}^{t i}$ is defined by reference to the indigenous total solids $m_{\mathrm{TS}}^{t}{ }^{0}$ given by:

$$
\begin{aligned}
\xi_{W}^{t i} & =\frac{m_{W}^{t}{ }^{i}}{m_{\mathrm{TS}}^{t}{ }^{0}}=\frac{m_{\mathrm{sample}}^{t i}-\left(m_{\mathrm{RCO}}^{t i}+m_{\mathrm{TS}}^{t}{ }^{0}\right)}{m_{\mathrm{TS}}^{t}{ }^{0}} \\
& =\frac{m_{\mathrm{sample}}^{t i}-m_{\mathrm{TS}}^{t i}}{m_{\mathrm{TS}}^{t}{ }^{0}}
\end{aligned}
$$

In the following, total dry solids coming from the dewatered sludge will be qualified as "indigenous," and their mass will be symbolized by $m_{\mathrm{TS}}^{t}{ }^{0}$.

\section{Experimental Protocol for Discontinuous Weighing}

To construct the fry-drying curve using the discontinuous method, fry-drying experiments were stopped at different times. Immediately after its removal from the oil bath, the sludge sample was immersed in liquid nitrogen at $-196^{\circ} \mathrm{C}$ to stop the water evaporation and thus avoid any underestimation of the sample mass. Moisture content defined by the discontinuous method $\xi_{W \text { disc }}^{t i}$ is the reference moisture content and was computed according to Eq. (4).

\section{Experimental Protocol for Continuous Weighing}

The experimental protocol implemented with the continuous weighing method is schematized in Fig. 4. In order to monitor the loss weight of the system formed by the fryer, the oil bath, and the sample, the scale placed under the deep-fat fryer is tared before the beginning of the fry drying experiment (period A in Fig. 4). Then, the metallic

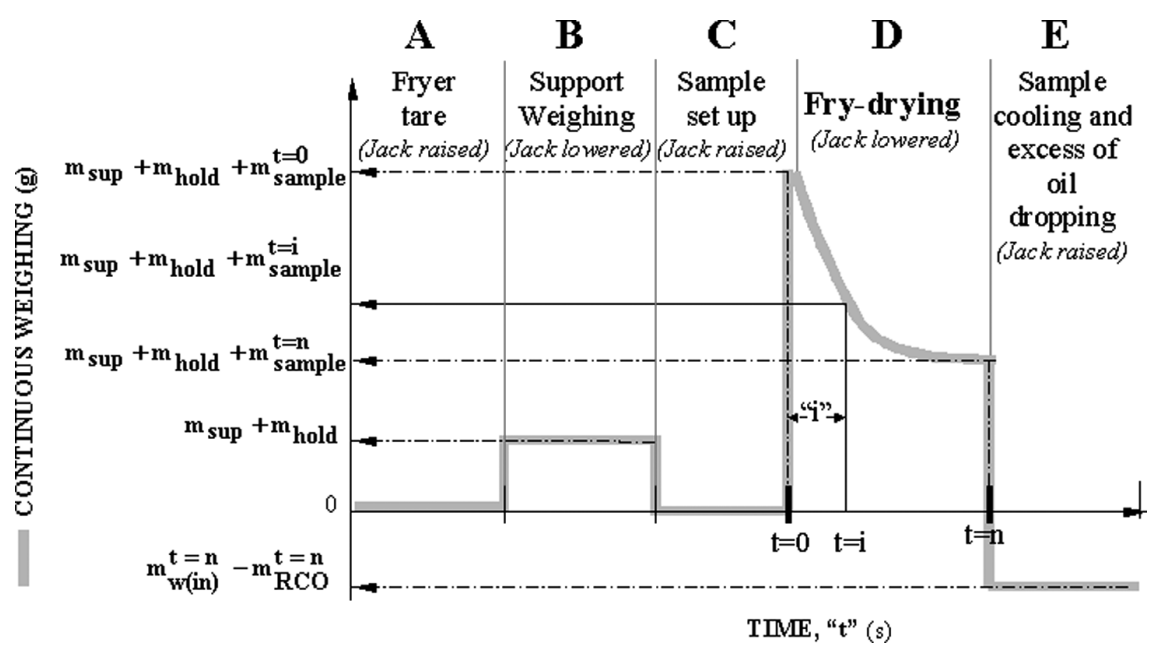

FIG. 4. Continuous weighing during the fry-drying of sewage sludge. 


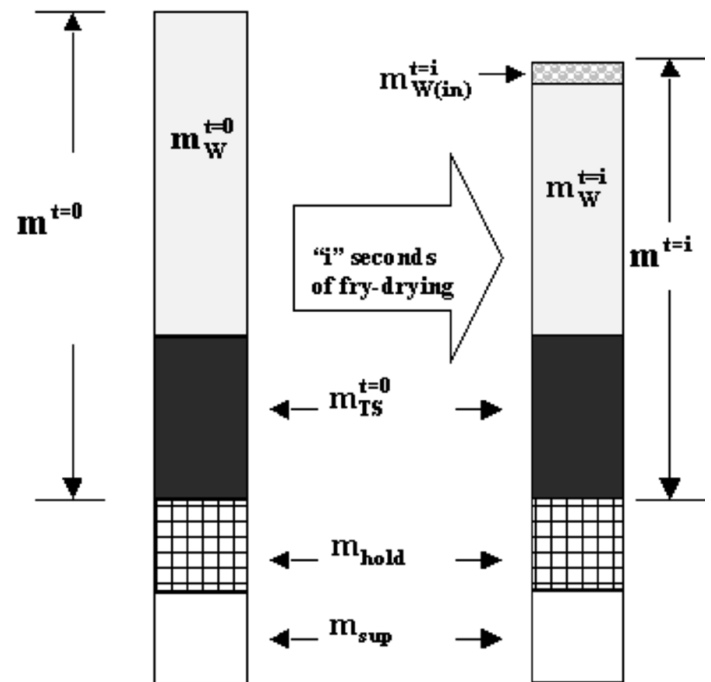

FIG. 5. Monitored masses that are included in the continuous weighing.

support, to which the sludge will be hung during frying, is set on the fryer walls and its mass ( $m_{\text {sup }}$ ) recorded (period B in Fig. 4). During the period C in Fig. 4, the jack is raised and the full sample container hold on the metallic support. At $t=0$, the jack is lowered again and the fry-drying experiment begins (period D in Fig. 4). The scale detects the masses added to the system (i.e., the metallic support mass $m_{\text {sup }}$, the sample holder mass $m_{\text {hold }}$, and the mass of the sample itself $m_{\text {sample }}^{t 0}$ ) and monitors the mass loss of the fryer, which corresponds to the mass of water leaving the fryer in the vapor state. As noted before, the monitored weight loss is only one part of the water losses. The other, which will be called $m_{W(i n)}^{t i}$, is trapped in the oil bath and its mass is accounted in the continuous weighing as schematized in Fig. 5.

\section{Data Adjustment}

For the same experimental conditions, the continuous and discontinuous weighing methods are compared. The recorded masses are divided by the initial mass of total dry solids to yield the moisture contents:

$$
\xi_{W \text { cont }}^{t i}=\frac{m_{W \text { cont }}^{t i}}{m_{\mathrm{TS}}^{t 0}}=\frac{m_{W}^{t}{ }^{i}+m_{W(i n)}^{t i}}{m_{\mathrm{TS}}^{t}{ }^{0}}
$$

and

$$
\xi_{W \text { disc }}^{t i}=\frac{m_{W}^{t}{ }^{i}}{m_{\mathrm{TS}}^{t}{ }^{0}}
$$

As expected the drying kinetics of the sludge sample are underestimated by the continuous method throughout the experiment. The difference between the two curves is due to the liquid water $m_{W(i n)}^{t n}$ trapped in the oil bath. At the end of the drying process, this quantity can be deduced from the difference between these two curves:

$$
m_{W(i n)}^{t}{ }^{n}=m_{\mathrm{TS}}^{t}{ }^{0}\left(\xi_{W \text { cont }}^{t n}-\xi_{W \text { disc }}^{t n}\right)
$$

In order to provide an acceptable estimation of the drying kinetics of the sample using the continuous method, an assumption should be made regarding the rate of trapping liquid water in the oil bath. It was considered that liquid water accumulates in the oil bath forming a semi-stable water-in-oil emulsion, ${ }^{[42]}$ which is a dispersion of two immiscible liquids where the resulting mixture will separate only after long periods of time. In that configuration, the recycled cooking oil would be the continuous phase and the small mass of liquid water divided into micro droplets would be the dispersed phase.

According to Peters, ${ }^{[43]}$ in very general terms, droplets are formed by stress being imparted to a large primary drop, causing elongation of all or part of it, followed by development of surface wave growth to the point of instability, whereby the primary drop breaks into droplets and often smaller satellite droplets. The stress source in fry-drying is supposed to be the rapid flow of the water vapor moving through the wet capillary network inside the sample. Consequently, the disruption of a plane surface separating two bulk phases, necessary to produce drops, threads, or misshaped lumps of dispersed phase can be achieved via turbulent eddies, surface ripples, and Rayleigh-Taylor and Kelvin-Helmotz instabilities. ${ }^{[44]}$ According to that, the liquid water droplets carried by the vapor stream should remain in the dispersing phase (RCO) over all the experiment.

In order to stabilize the newly formed droplets of the dispersed phase against coalescence, emulsifiers (surface active substances, surfactants) and stabilizers must be contained in the emulsion. Stabilizers actually lead to improve droplet disruption at constant energy density. For the fry-drying test, the free fat acids and the polar compounds formed during the oil degradation may act as surfactants. ${ }^{[24,27,34,45,46]}$

There are number of difficulties in examining the roles of the factors that control the emulsification process, such as the viscous and elastic properties of the two phases, the interfacial properties, or even the flow conditions. ${ }^{[43]}$ Indeed, the key difficulty is that, in a practical sense, emulsification does not take place under steady conditions, but under dynamic conditions where time scales are extremely short. Nevertheless, it is accepted that, for a set of components and under isothermal conditions, the formation of the emulsion depends mainly on the mechanical energy input. ${ }^{[42]}$ In our case, this energy would be brought by the agitation of the removed water during the fry-drying at a rate given by $-\left(d m_{W}^{t}{ }^{i}\right) / d t$. This is consistent with the observations made by Vitrac et al., ${ }^{[39]}$ who reported that the greatest water losses in liquid state occurred during the first instants of frying, where the percentage 
of discrepancy and $-\left(d m_{W}^{t}{ }^{i}\right) / d t$ were the highest. As a result, it is reasonable to assume that the rate of formation of emulsified water is proportional to the drying rate,

$$
\frac{d m_{W(i n)}^{t}}{d t}=-\alpha \frac{d m_{W \text { cont }}^{t}}{d t}
$$

Assuming that $\alpha$ is constant, Eq. (8) can be written in integrated form,

$$
\alpha \approx \frac{m_{W(i n)}^{t i}}{m_{W}^{t}{ }^{0}-m_{W(i n)}^{t i}}
$$

Or introducing the moisture contents $\xi_{W \text { cont }}$ and $\xi_{W}$,

$$
\alpha=\frac{\xi_{W \text { cont }}^{t i}-\xi_{W}^{t}{ }^{i}}{\xi_{W \text { cont }}^{t}-\xi_{W \text { cont }}^{t i}}
$$

As noted, the actual moisture content of the sample $\xi_{W}$ is well approximated by the discontinuous method, then $\alpha$ may be calculated using the following equation:

$$
\alpha=\frac{\xi_{W \text { cont }}^{t}-\xi_{W \text { disc }}^{t n}}{\xi_{W \text { cont }}^{t 0}-\xi_{W \text { cont }}^{t n}}
$$

As shown in Fig. 6, in spite of the simplifications, the drying curve, i.e., $\xi_{W}^{t}{ }^{i}$ versus time, calculated from Eq. (10) is in good agreement with the discontinuous measurements $\xi_{W \text { disc }}^{t}$.

The values for $\alpha$ (i.e., the ratio between the liquid water trapped in the oil bath and the vapor water losses) depend on a variety of parameters (see Fig. 7). In Fig. 7a, a decrease of $\alpha$ is observed when the frying temperature increases. This supports the semi-stable emulsion hypothesis, which qualitatively provides the same trends and is consistent with the observation that higher temperatures destabilize emulsions. ${ }^{[42]}$

In addition, it was deduced from Fig. $7 \mathrm{~b}$ that runs using the smaller sample diameter lead to higher values for $\alpha$. In fact, the very intense heat transfer rate for the smaller

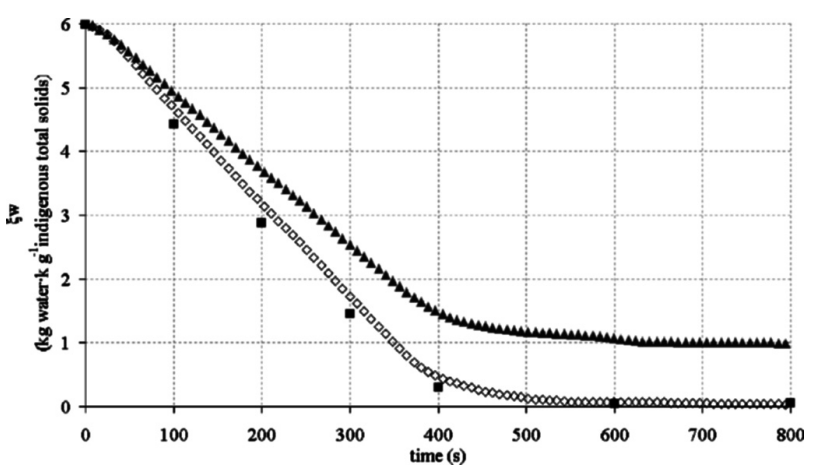

FIG. 6. Comparison of the drying curves $\left(T=160^{\circ} \mathrm{C}\right.$ and $\left.D=15 \mathrm{~mm}\right)$ obtained by the continuous $(\boldsymbol{\Delta}) \xi_{W}$ cont , adjusted $(\diamond) \xi_{W}$, and discontinuous $(\square) \xi_{W_{\text {disc }}}$ methods.
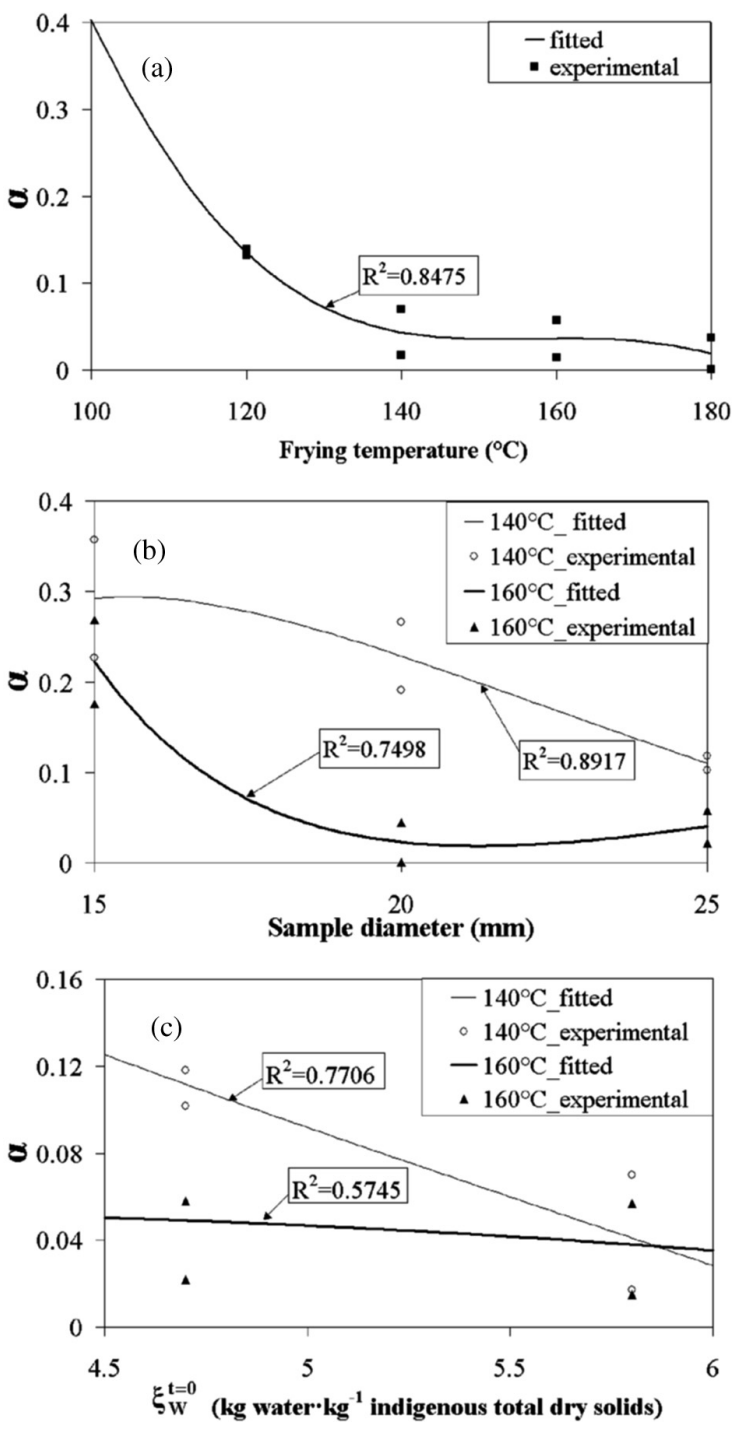

FIG. 7. Effect of the frying temperature (a), the diameter (b), and the initial moisture content of the sample (c) on the values of $\alpha$.

sample gives a very high drying rate $-\left(d m_{W}\right) / d t$, which is linked with the agitation of the oil bath and therefore with the amount of emulsified water. Finally, it seems that initial moisture content has only a slight effect on $\alpha$ compared with other parameters (Fig. 7c).

\section{Data Analysis}

An analysis of heat and mass transfers during fry-drying of sewage sludge was based on the drying and temperature core curves. Duplicate experiments were done for different operational conditions given in Table 4 and fitted by the cubic spline estimation method using a conventional curve-fitting program (Table Curve 2D v. 5.0, STATCON, 
TABLE 4

Operating parameters for the frying tests

\begin{tabular}{lcccc}
\hline Number of trials & $\begin{array}{c}\text { Temperature } \\
\left({ }^{\circ} \mathrm{C}\right)\end{array}$ & $\begin{array}{c}\text { Initial moisture content } \\
\left(\mathrm{kg} \text { water } \cdot \mathrm{kg}^{-1} \text { total solids }\right)\end{array}$ & Diameter $(\mathrm{mm})$ & Frying time (s) \\
\hline 2 & 120 & 5.8 & 25 & 3000 \\
2 & 140 & 5.8 & 25 & 1200 \\
2 & 140 & 4.6 & 25 & 1360 \\
2 & 140 & 4.5 & 20 & 1215 \\
2 & 140 & 4.7 & 15 & 950 \\
2 & 160 & 5.8 & 25 & 1000 \\
2 & 160 & 4.6 & 25 & 1060 \\
2 & 160 & 4.6 & 20 & 720 \\
2 & 160 & 4.4 & 15 & 520 \\
2 & 180 & 5.8 & 25 & 1000 \\
\hline
\end{tabular}

Witzenhausen, Germany). The drying rate was calculated from the drying curve by numerical differentiation. The results were finally smoothed, after testing different smoothing estimations proposed by Table Curve 2D, using the mathematical algorithm Loess with $10 \%$ of smoothing.

\section{Visualization of Fry-Drying of Sewage Sludge}

Images of sludge fry-drying were recorded using a digital video camera recorder (DCR-PC103 E, Sony ${ }^{\circledR}$, Tokyo, Japan). The fry-drying experiment was performed in a transparent apparatus made from a PYREX ${ }^{\circledR}$ crystallizer ( $V=3000 \mathrm{~L}$, Bibby Sterilin Ltd, England). This was filled with $2.0 \mathrm{~kg}$ of peanut oil (Lapalisse, France) and placed on a large capacity hot-plate stirrer (mod. HB502, Bibby Sterilin Ltd, Staffordshire, UK). A cylindrical sample $(L=13 \mathrm{~mm}$ and $D=25 \mathrm{~mm}$ ) of about $85 \mathrm{~g}$ of sewage sludge was immersed in hot oil in a sample container similar to those used in the quantitative frying tests. A uniform backlight was obtained with a quartz halogen illuminator (Fiberlite ${ }^{\circledR}$, mod: MI-150, Dolan-Jenner Industries, Boxborough, USA).

\section{RESULTS AND DISCUSSION}

\section{Typical Fry-Drying Curves for Sewage Sludge}

\section{Reproducibility of the Fry-Drying Measurements}

The results shown as a reference throughout this section were obtained when the fry-drying was carried out at

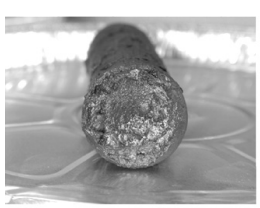

(a)

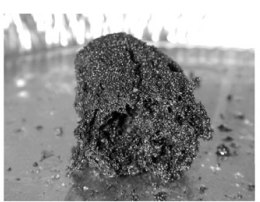

(b)

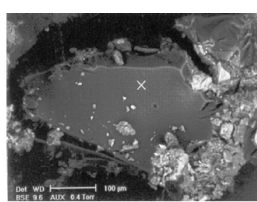

(c)
FIG. 8. Samples of mechanically dewatered (a) and fry-dried (b) sludge and microstructure of the fry-dried sludge (c).
$T_{\text {oil }}=160^{\circ} \mathrm{C}$, using a cylinder sample $(145 \mathrm{~mm}$ long and $25 \mathrm{~mm}$ in diameter) of sewage sludge having an initial moisture content of $5.8 \mathrm{~kg}$ water $\cdot \mathrm{kg}^{-1}$ total solids. Figures $8 \mathrm{a}$ and $\mathrm{b}$ show the sewage sludge sample before and after the process. Fry-dried sludge is a black porous matrix made of solid sludge particles covered with a thin layer of oil. The microphotography provided gives an idea of its microstructure (see Fig. 8c).

Figure 9 shows the spread of two runs at the reference conditions. Total fry-drying times are reproducible. Indeed, once immersed into the heated oil, it takes about $1100 \mathrm{~s}$ for the sludge sample to be almost completely dried (Fig. 9a). The reproducibility of the continuous drying curves is noteworthy (Fig. 9a). The maximal difference between the two experimental curves with respect to the fitted curve is less than $5 \%$. Indeed, reported fry-drying curves for foods, which are derived from a discontinuous weighing, exhibit experimental dispersions higher than $10 \%{ }^{[2,39]}$

Reproducibility of the results can also be observed with the heating profile of the sample core (see Fig. 9b). In the heating curve, two regions can be distinguished on both sides of the water boiling temperature $T_{\text {boil }}$ (i.e., $102104^{\circ} \mathrm{C}$ ). Spread of the monitored temperature profiles for the different replicates is slight as soon as the temperature remains below $T_{\text {boil }}$, but there are some differences from one test to another for temperatures located above $T_{\text {boil }}$, particularly for the surface temperature (i.e., $T$ at $\mathrm{r} \approx 12.5 \mathrm{~mm}$ in Fig. 9b). This variability may be due to differences in the random steam pathways formed inside the samples during boiling and the oil uptake mechanisms that take place.

Finally, the pattern of the drying rate curve (see Fig. 9c) has two maxima unlike most conventional frying studies. Usually the drying kinetics exhibit only one maximum at the early stage followed by a falling drying rate period. ${ }^{[37,47,48]}$ This unusual curve with two maxima is not considered to be a numerical artefact and consequently requires physical explanation. 


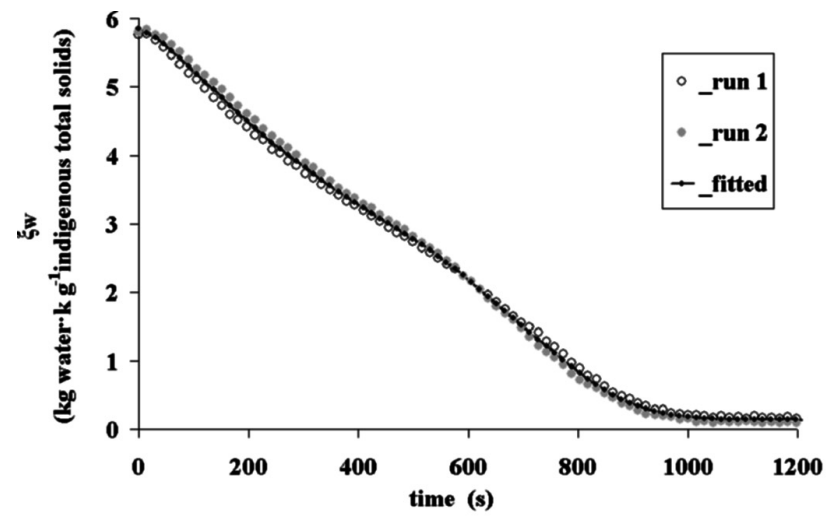

(a)

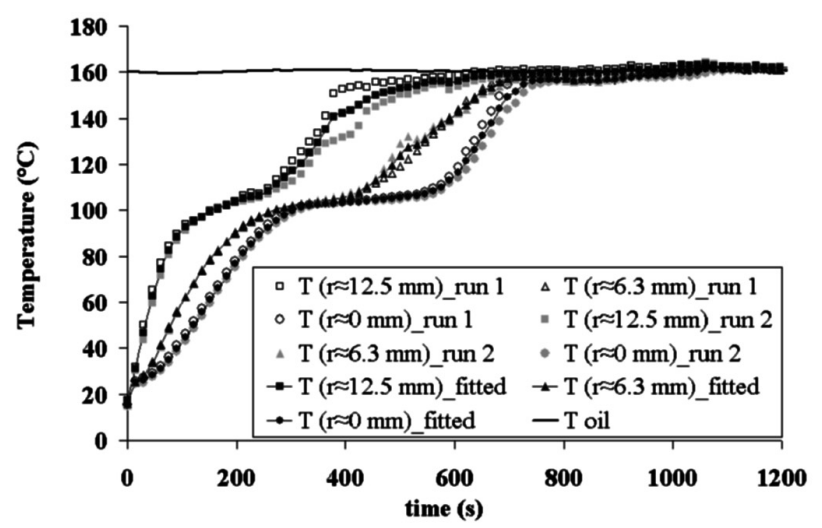

(b)

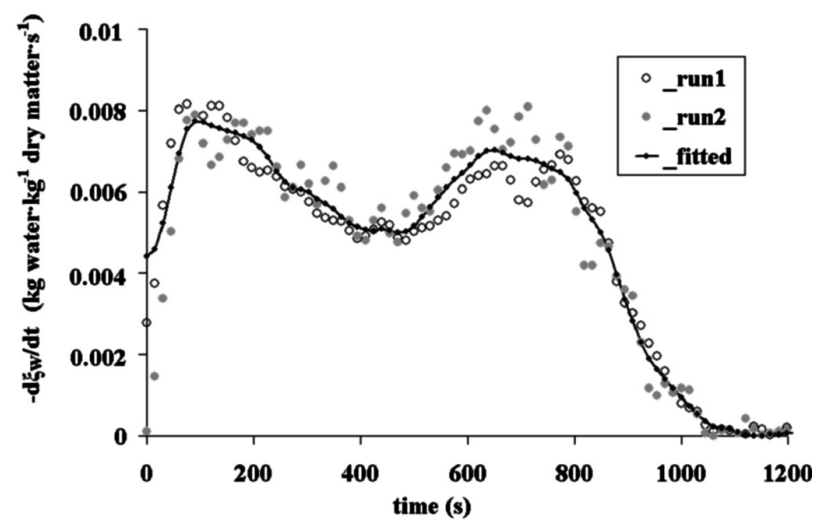

(c)

FIG. 9. Dispersion between the raw and fitted data of the drying (a), heating (b), and drying rate (c) curves of the fry-drying of sewage sludge at $160^{\circ} \mathrm{C}$ using a sample diameter of $25 \mathrm{~mm}$.

\section{Mapping of the External Heat Transfer Coefficient}

Heat is transferred from the heated oil to the surface of the sample by convection. Due to the intense oil agitation, surface heat transfer coefficient $h_{0}(t)$ generally presents values between some hundreds to some thousands of
$\mathrm{W} \cdot \mathrm{m}^{-2} \cdot \mathrm{K}^{-1}{ }^{[49-53]}$ An interesting tool to relate the variation of $h_{0}$ and the water loss is to observe the different boiling regimes that occur during the immersion frying. ${ }^{[47]}$ Figure 10 gives some boiling images of the fry-drying of sewage sludge captured at different times in the process.

At the beginning of the experiment, immediately after immersing the sample into the heated oil bath (see Fig. 10a), no-bubbling stage was observed. In those circumstances, the value of $h_{0}=h_{f c}$, where the free convection coefficient $\left(h_{f c}\right)$ can be estimated using typical equations for free convection across a horizontal cylinder ${ }^{[54]}$ given by Eqs. (12) to (14).

$$
\mathrm{Nu}=a(\mathrm{Ra})^{b}
$$

where $a$ and $b$ given by Whitaker ${ }^{[54]}$ are 0.52 and 0.25 , respectively, and

$$
\begin{gathered}
\mathrm{Nu}=\frac{h_{f c} D}{k} \\
\mathrm{Ra}=\frac{g \beta\left(T_{\text {oil }}-T_{\text {surface }}\right) D^{3}}{\nu \varepsilon}
\end{gathered}
$$

A value of $h_{f c}=238 \mathrm{~W} \cdot \mathrm{m}^{-2} \cdot \mathrm{K}^{-1}$ was estimated for the conditions of our case of study (i.e., horizontal cylinders, $D=25$ having an initial $T_{\text {surface }}=20^{\circ} \mathrm{C}$ and immersed in oil at $T_{\text {oil }}=160^{\circ} \mathrm{C}$; kinematic viscosity, $\nu=3.6 \times 10^{-6} \mathrm{~m}^{2} \cdot \mathrm{s}^{-1} ;$ heat diffusivity, $\varepsilon=1.3 \times 10^{-7}$ $\mathrm{m}^{2} \cdot \mathrm{s}^{-1}$; thermal volumetric expansion coefficient, $\beta=7.7 \times$ $10^{-5} \mathrm{~K}^{-1} ;$ and heat conductivity, $k=263 \times 10^{-3}$ $\left.\mathrm{W} \cdot \mathrm{m}^{-1} \cdot \mathrm{K}^{-1}\right)$.

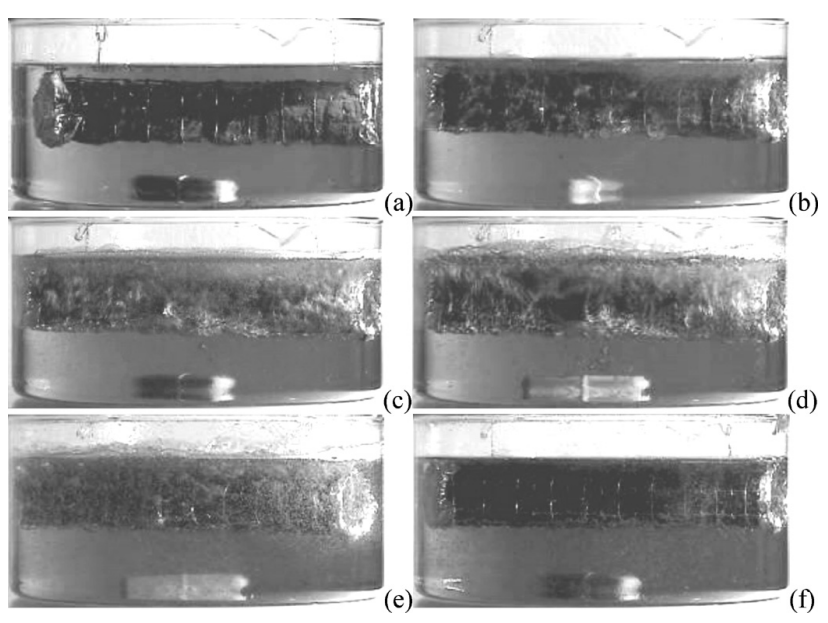

FIG. 10. Images of different boiling regimes observed during fry-drying of sewage sludge. 
Due to the high temperature of the oil, this no-bubbling stage is short and in less than $5 \mathrm{~s}$ the surface of the sample starts to boil as some discrete vapor bubbles (see Fig. 10b), which suddenly turns to become a more dense blanket of bubbles that covers the sample completely (see Fig. 10c). During the boiling period an approximated value of $h_{0}(t)$ can be calculated directly from the monitored temperature and water loss data, ${ }^{[47-50]}$ using the enthalpy balance given by Eq. (15)

$$
h_{0}(t)=-m_{\mathrm{TS}}^{t}{ }^{0} \frac{d \xi_{W}}{d t}\left[\frac{\Delta H_{\mathrm{vap}}}{A\left(T_{\mathrm{oil}}-T_{\mathrm{surface}}\right)}\right]
$$

With Eq. (15), it is assumed that transferred convective heat is used essentially for boiling and that the surface area of the sample $A$, as well as the latent heat of vaporization $\Delta H_{\text {vap }}$ at $T_{\text {boil }}$, remains constant for the duration of the process.

The calculated $h_{0}(t)$ values are given in Fig. 11. The pattern is similar to that obtained for the frying of thick tubes of potato samples. ${ }^{[4]}$ It starts with a moderate increase during the first seconds of the experiment and then stabilizes at a quasi-constant value. Thereafter, the heat transfer coefficient increases sharply to its peak value close to $2500 \mathrm{~W} \cdot \mathrm{m}^{-2} \cdot \mathrm{K}^{-1}$ and then decreases radically to almost zero at the end of the process.

Maximum $h_{0}$ values of some thousands of $\mathrm{W} \cdot \mathrm{m}^{-2} \cdot \mathrm{K}^{-1}$ are not surprising. Hubbard and Farkas ${ }^{[50]}$ reported that for frying cylinders potatoes $(16 \mathrm{~mm}$ diameter and $9 \mathrm{~mm}$ length) at $180^{\circ} \mathrm{C}, h_{0}$ was initially to about $300 \mathrm{~W} \cdot \mathrm{m}^{-2} \cdot \mathrm{K}^{-1}$ and then increased sharply to $1100 \mathrm{~W} \cdot \mathrm{m}^{-2} \cdot \mathrm{K}^{-1}$, whereas Vitrac et al. ${ }^{[52]}$ observed peaks higher than $2000 \mathrm{~W} \cdot \mathrm{m}^{-2} \cdot \mathrm{K}^{-1}$ for the cassava crisps fried at $160^{\circ} \mathrm{C}$.

It is accepted that the enhancement of $h_{0}$ in frying being greater than forced convection ${ }^{[55]}$ is due to the presence of the vapor bubbles and the bridges formed between the surface, and the liquid and vapor phases. ${ }^{[27,53]}$ As a result,

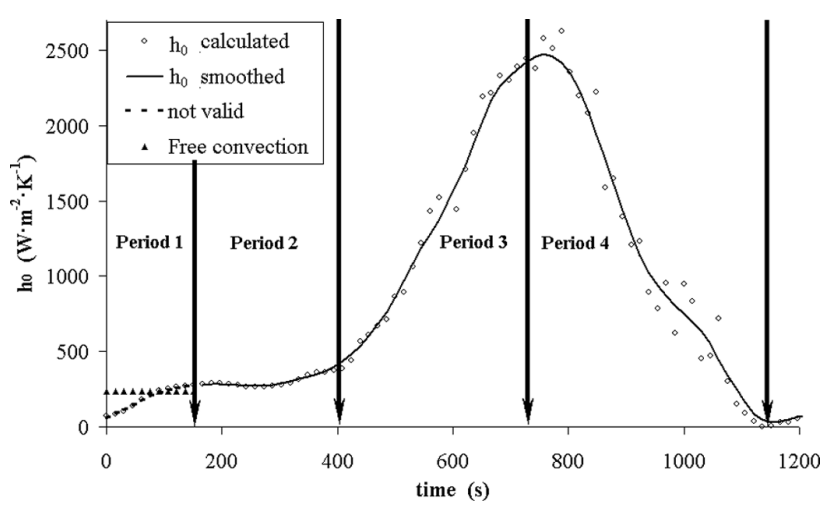

FIG. 11. Mapping of the convective heat transfer coefficient for frydrying at the reference conditions. the enhancement of the external heat transfer coefficient compared to free convection is closely related to the water losses. ${ }^{[48,49]}$

It can be seen in Fig. 11 that there are four welldifferentiated periods: A first heating period where natural convection and boiling mode overlap during the first $150 \mathrm{~s}$. Equation (15) is not valid in the first instants of fry-drying due to heat accumulation and internal conduction effects. The constant value of $h_{f c}=238 \mathrm{~W} \cdot \mathrm{m}^{-2} \cdot \mathrm{K}^{-1}$ is more representative of the first instants of the frying test.

Then, the formation of a vapor film implies a momentary stabilization in the hydrodynamics of the oil bath that may be related to a second period, where $h_{0}$ gets close to values in between 260 and $290 \mathrm{~W} \cdot \mathrm{m}^{-2} \cdot \mathrm{K}^{-1}$ as is shown in Fig. 11 between 150 and $400 \mathrm{~s}$ after the beginning of the experiment.

After a certain time, the film is no longer stable, gets thicker, and is accompanied with some discrete bubbles appearing at an irregular frequency (see Fig. 10d). This third period could be assimilated to the part of the experiment where the values of $h_{0}$ increase sharply until a maximum, close to $2500 \mathrm{~W} \cdot \mathrm{m}^{-2} \cdot \mathrm{K}^{-1}$ and located at a frying time of about $700 \mathrm{~s}$ (Fig. 11). Then, a fourth period is noted, where the agitation of the oil decreases, the film is no longer observed, and instead only some jets of vapor bubbles keep escaping slowly from the sample at an apparent decreasing rate (see Fig. 10d). Finally, the sample stops boiling (Fig. 10e).

\section{Interpretation of the Mechanisms Involved in the Fry-Drying of Sewage Sludge}

In order to give a qualitative interpretation of the mechanisms involved in the fry-drying of sewage sludge, the four previously differentiated periods were located over the drying rate curve (Fig. 12a) and Krischer curve (Fig. 12b), which are co-plotted with the heating curves monitored at different depths in the sample, namely at the surface (i.e., $r \approx 12.5 \mathrm{~mm}$ ), at the geometric center (i.e., $\mathrm{r} \approx 0 \mathrm{~mm}$ ), and in the middle between those points (i.e., $r \approx 6.3 \mathrm{~mm}$ ). The following sections give an in-depth analysis of every period.

First Period: Initial Heating Period. The first period covers the first $150 \mathrm{~s}$ that follow the immersion of the sample in the heated oil. Figure 12a shows that the water loss from the sample due to the surface moisture evaporation takes place almost instantaneously after immersion and the drying rates increase until a first maximum. Moreover, the wet surface heats up rapidly by convection from the oil to the boiling point of the liquid water (i.e., $T_{\text {boil }} \approx 102104^{\circ} \mathrm{C}$ ), while the heat is transferred by conduction from the surface to the geometric center of the sample. Thus, one fraction of the convectively transferred heat is accumulated in the inner 


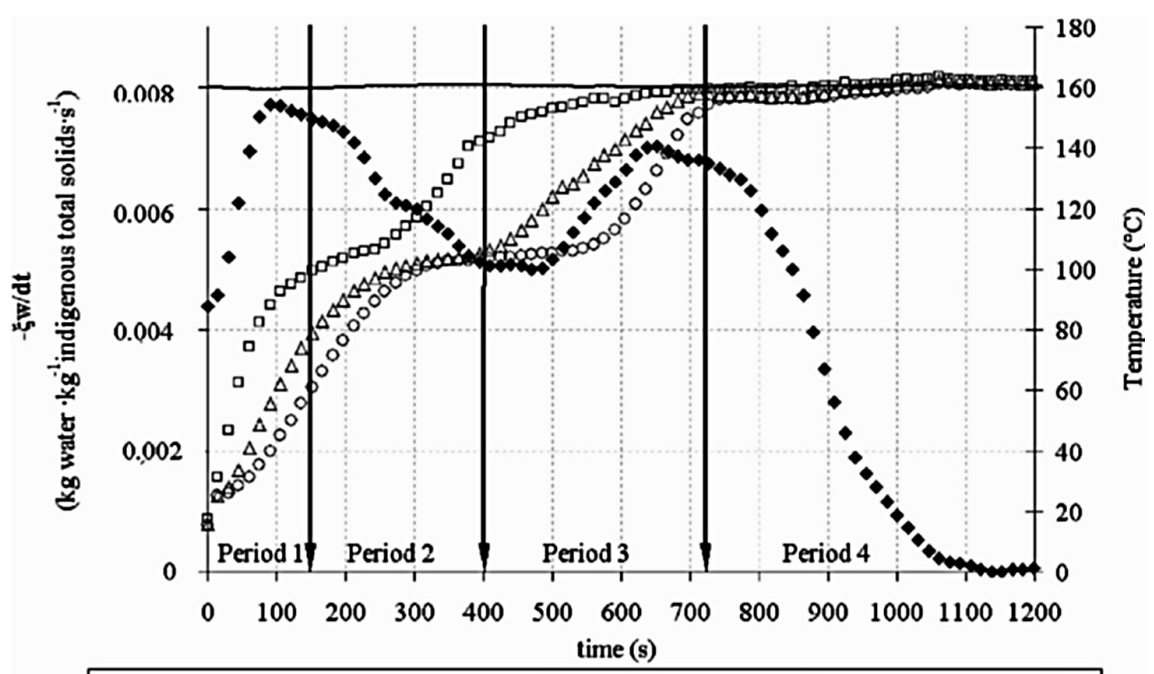

- $-\xi_{\mathrm{w}} / \mathrm{dt}-\mathrm{T}_{\mathrm{ol}} \circ \mathrm{T}(\mathrm{r} \approx 12.5 \mathrm{~mm}) \_$fitted $\Delta \mathrm{T}(\mathrm{r} \approx 6.3 \mathrm{~mm}) \_$fitted $\circ \mathrm{T}(\mathrm{r} \approx 0 \mathrm{~mm}) \_$fitted

(a)

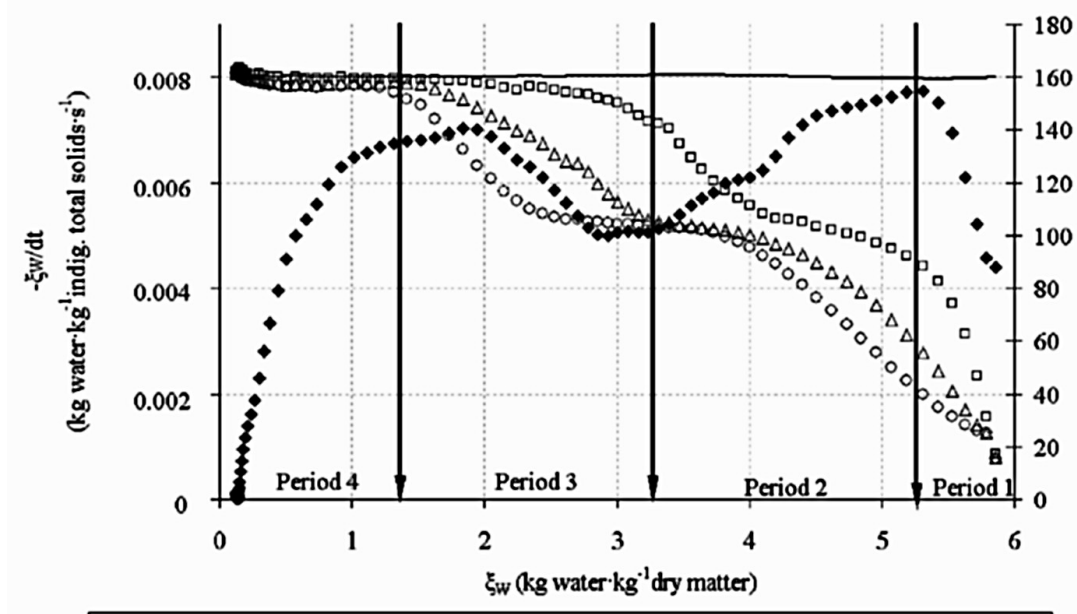

ठู

- $-\xi_{\mathrm{w}} / \mathrm{dt}-\mathrm{T}_{\text {oil }} \circ \mathrm{T}(\mathrm{r} \approx 12.5 \mathrm{~mm}) \_$fitted $\Delta \mathrm{T}(\mathrm{r} \approx 6.3 \mathrm{~mm}) \_$fitted $\circ \mathrm{T}(\mathrm{r} \approx 0 \mathrm{~mm}) \_$fitted

(b)

FIG. 12. Co-plotted drying rate-heating curves (b) and Krischer heating curves (c) of fry-drying at the reference conditions.

layers of the sample and the other is used for boiling, resulting in an enhancement of $h_{0}(t)$ in some tens of $\mathrm{W} \cdot \mathrm{m}^{-2} \cdot \mathrm{K}^{-1}$ with respect to $h_{f c}$ (Fig. 11).

Second Period: Fry-Drying of Sewage Sludge as a Boiling Front Process. In this study, it was estimated that drying rate and heating profiles observed for the fry-drying sewage sludge from $150 \leq t \leq 400 \mathrm{~s}$ (Fig. 12a) correspond to those of a process controlled mainly by heat transfer, which is known as moving boundary ${ }^{[56,57]}$ or Stefan problem. ${ }^{[58]}$ Indeed, when the surface of the sample loses the moisture, two regions start to develop within the sample, a crust and a core (see Fig. 13). These two regions are defined by the liquid vapor interface created within the sample due to evaporation of water. Since the crust results from the water removal, its thickness increases over the duration of the process through consumption of the core resulting in a displacement of the boiling front. Consequently, heat is transferred to the sample from the oil by convection at the oil/sample interface, and then to the geometric center of the sample via conduction trough the crust and the core (see Fig. 14).

The process is controlled mostly by the heat transfer mechanisms, where heat flux is driven by the temperature difference between the oil and the boiling front ${ }^{[15]}$ against 


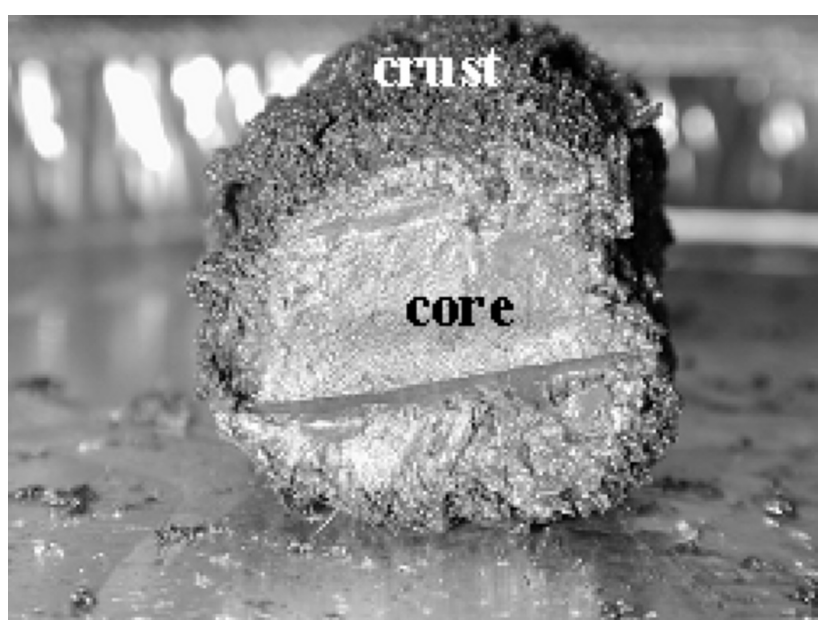

FIG. 13. Regions within the cross section of a partially fry-dried sample.

a series of external $\left[\Re_{\text {external }}(t)\right]$ and internal $\left[\Re_{\text {internal }}(t)\right]$ resistances given by:

$$
\begin{aligned}
\Phi(t) & =\frac{T_{\text {oil }}-T_{\text {surface }}(t)}{\Re_{\text {external }}(t)}=\frac{T_{\text {surface }}(t)-T_{\text {boil }}}{\Re_{\text {internal }}(t)} \\
& =-m_{\mathrm{TS}}^{t 0} \Delta H_{\text {vap }} \frac{d \xi_{W}(t)}{d t}
\end{aligned}
$$

Figure 15 shows the values of the external, internal, and overall thermal resistances calculated from Eq. (16) at the end of period two and the beginning of period three when $T_{\text {center }} \approx T_{\text {boil }}=102^{\circ} \mathrm{C}$.

During the first part of the second period, the estimated value of the internal resistance is slight compared to the external resistance $\left(\Re_{\text {external }}=2.5 \times 10^{-1} \mathrm{~K} \cdot \mathrm{W}^{-1}\right)$. This shows that for the first instants of the second period, fry-drying is limited by the external conditions. However, for the last instants of period 2 when the thickness of the crust increases due to the sample drying, the rise

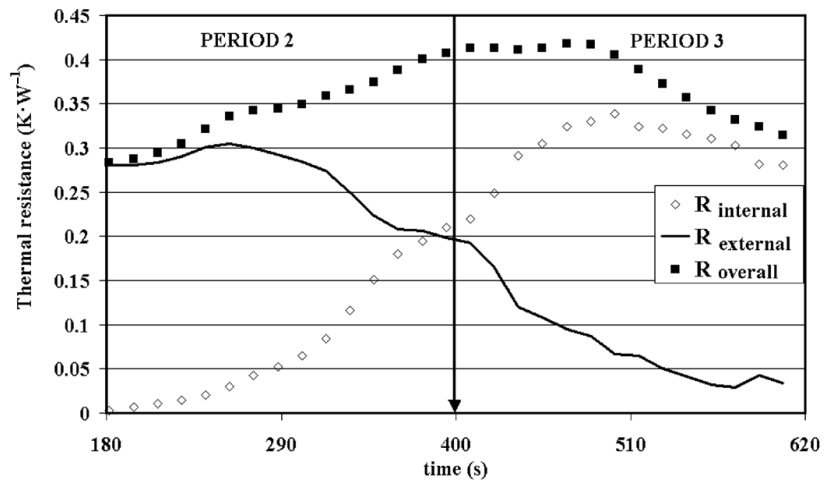

FIG. 15. Thermal resistances calculated during periods 2 and 3 of the fry-drying for sewage sludge.

of the internal resistance is accompanied by a decrease in the external one, which continues during the third period. The global effect of these two resistances gives an effective increase of the thermal resistance $\left(\Re_{\text {overall }}\right)$ during period 2 from 2.7 to $4.1 \times 10^{-1} \mathrm{~K} \cdot \mathrm{W}^{-1}$, which explains the falling drying rate (Fig. 12).

Equation (16) can also be presented in the form of Eq. (17), which allows to calculate an approximate value of the apparent thermal conductivity of the crust $\left(k_{\mathrm{app}}\right)$ from the experimental measurements obtained during the second period.

$$
\begin{aligned}
\Phi(t) & =\frac{T_{\text {oil }}-T_{\text {surface }}}{\frac{1}{2 \pi R L h_{0}(t)}}=\frac{T_{\text {surface }}-T_{\text {boil }}}{\frac{1}{2 \pi L k_{\text {app }}(t)} \ln \left(\frac{R}{r_{\text {boil }}(t)}\right)} \\
& =-m_{\mathrm{TS}}^{t}{ }^{0} \frac{d \xi_{W}}{d t} \Delta H_{\text {vap }}
\end{aligned}
$$

where $h_{0}$ is the heat transfer coefficient (Fig. 11), and $k_{\text {app }}$ is the apparent thermal conductivity of the crust having a thickness $\left[r_{\text {boil }}(t)\right]$ that separates the wet part of the material from the heated oil (Fig. 16).

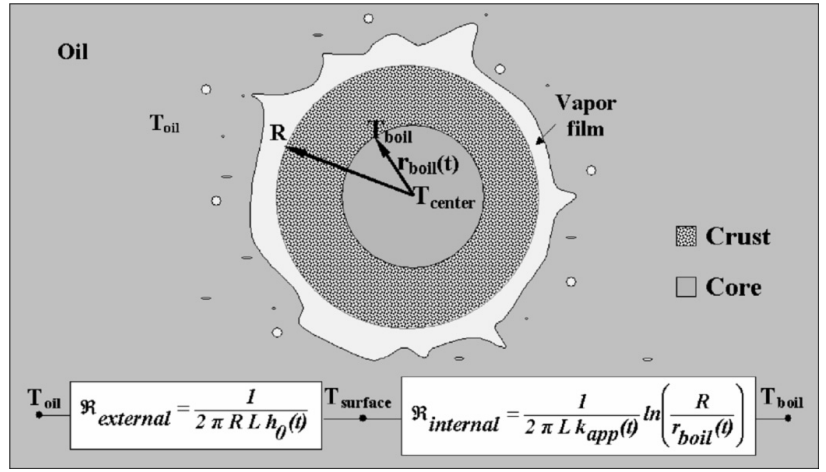

FIG. 16. Schematized regions within the cross section of a sewage sludge sample during period 2 of fry-drying.

FIG. 14. Semi-infinite slab undergoing frying according to Farkas et al. ${ }^{[47]}$ 


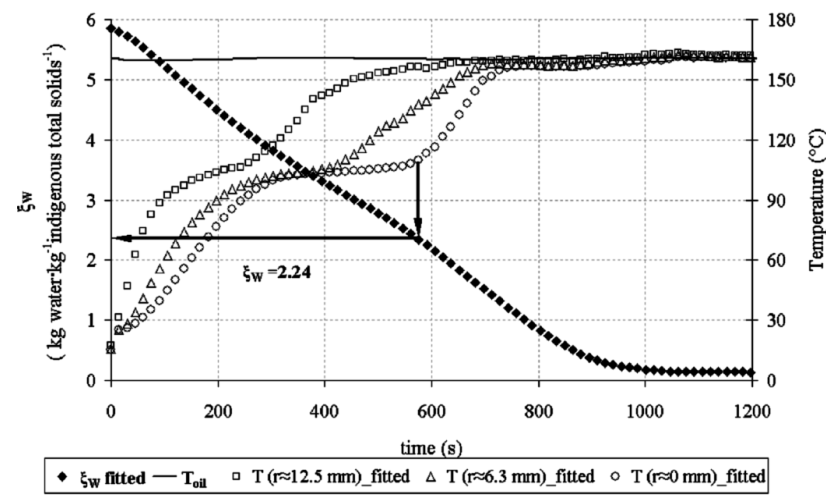

FIG. 17. Co-plotted drying-heating curves at the reference conditions.

Due to the difficulty to precisely define the location of this layer, only an approximate order of magnitude for the internal thermal resistance was calculated from Eq. (17). It was done when the thermocouple located at $r \approx 6.3 \mathrm{~mm}$ monitors a temperature close to $T_{\text {boil }} \approx 102^{\circ} \mathrm{C}$ (i.e., at about $320 \mathrm{~s}$ ). The calculated value gives a $k_{\text {app }}=2.1 \mathrm{~W} \cdot \mathrm{m}^{-1} \cdot \mathrm{K}^{-1}$, which is an order of magnitude higher than typical values reported in food frying studies. ${ }^{[2]}$ Considering the reproducibility of the experimental measurements, it can be said that such high value actually occurs in the fry-drying of sewage sludge. A probable explanation may be provided by the large amounts of residual liquid water contained in the capillary channels formed by the solid particles in the crust. ${ }^{[21,37]}$ Indeed, it was observed that when the temperature at the center of the material $\left(T_{\text {center }}\right)$ starts to be located above $T_{\text {boil }}$, there is still about $40 \%$ of the initial moisture content of the sludge (Fig. 17), which is also a high value compared to the residual moisture found in the typical foods frying studies. ${ }^{[2]}$

As a consequence, in the thinner capillaries of the crust, the activity of water is lowered and thus the local boiling temperature is increased. ${ }^{[59,60]}$ Local temperature gradients can thus lead to condensation-vaporization effects at a very small scale, similarly to what occurs in micro-heat pipes. ${ }^{[61]}$ As a result, the effective thermal conductivity of the crust should be enhanced compared to pure conduction phenomena.

Third Period: Oil Impregnation. In most of the typical fried foods process, ${ }^{[37,47-50]}$ the falling drying rate period that starts in period 2 leads to the complete and final drying of the sample, accompanied by a gradual decrease of $h_{0}$ because of the sample dry up. In contrast, for the fry-drying of sewage sludge at about $400 \mathrm{~s}$, neither the falling rate period nor the constant values tend to decrease. Instead, a sharp increase in $h_{0}$ values was noted (Fig. 11), at the same instant that the falling drying rate stabilizes at a value close to $0.005 \mathrm{~kg}$ water $\cdot \mathrm{kg}^{-1}$ total dry solids $\cdot \mathrm{s}^{-1}$ (Fig. 12a).

The increase of $h_{0}$ seems to improve noticeably the heat transfer causing a rise for the drying rates values until a maximum located at $0.007 \mathrm{~kg}$ water $\cdot \mathrm{kg}^{-1}$ total dry solids $\cdot \mathrm{s}^{-1}$ (see Fig. 12a) that consumes almost all the free water still contained in the sample. Thus, the very intense internal boiling during the third fry-drying period (i.e., between 400 and $700 \mathrm{~s}$ ) explains the forced agitation in the oil bath observed in Fig. 10d, which will produce simultaneously an increase in the internal barrier and a reduction in the external one (see Fig. 15).

According to Eq. (15), the reason to expect such an increase of $h_{0}$ for a constant drying rate, is related to a rapid decrease of the temperature difference $\left(T_{\text {oil }}-T_{\text {surface }}\right)$, which supposes a rapid heating of the surface of the sample (see Fig. 12a). Heat accumulation may create some pressure gradients, ${ }^{[21]}$ which produce other force-driven mechanisms for the heat and mass transfers. These evidences added to the decrease of the overall thermal resistance (Fig. 15), suggest that the fry-drying is not longer controlled only by the conduction through the crust, as in period 2.

The hypothesis of a mechanism of oil impregnation as a moisture replacement ${ }^{[16,22,23]}$ that starts in the outer layers of the crust, seems to justify this rapid increase in the temperature at the outer layers. In fact, although oil uptake during immersion frying is extremely complex process and still not completely understood, it is widely accepted that:

1. High temperatures create significant internal evaporation and pressure generation (estimated at some tens of $\mathrm{kPa}$ for food products). ${ }^{[1]}$

2. This increases internally and externally the surface roughness, capillary network, and porosity where the oil is easily absorbed.

3. Finally, there is an internal pressure drop due to water loss, which creates a "vacuum effect" that enables further oil uptake.

According to that theory, the role of transport mechanisms driven by a pressure gradient gets an extent as important as that of heat transfer. In fact, internal pressure produces oil impregnation but also water moisture redistribution by capillarity and diffusivity through the whole sample. ${ }^{[2,17,18,21]}$ Thus, the two regions well defined in period 2 are not detected straightforwardly (see Fig. 18a) giving a pseudo-crust and core regions presented in Fig. 19, whose characteristics sensibly differ from those assumed in period 2. In fact, water liquid can migrate to the crust and water vapor or liquid can be present in discrete points in the core. Consequently, internal vaporization and oil impregnation phenomena are now and until about $720 \mathrm{~s}$ controlled by heat transfer and transport mechanisms in a same extent. At that time, the sample 

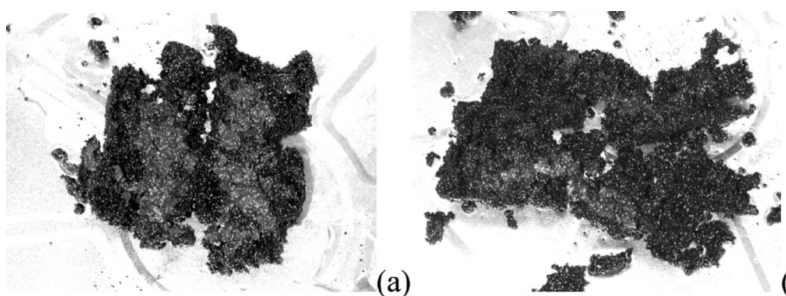

FIG. 18. Pictures of the cross section at times close to the beginning (a) and the end (b) of period 3 of fry-drying.

reaches a thermal equilibrium with the sample having still about $20 \%$ of the initial moisture content. The regions in the sample can no longer be assimilated to a core and crust configuration but rather to a porous media ${ }^{[59,60]}$ (see Fig. 18b).

The phenomenon of an oil impregnation occurring long after the beginning of the operation may sound contradictory with some authors, who report that oil uptake occurs from the very first moments of the frying process. ${ }^{[16,35,37,62]}$ In fact, all those works report oil contents determined postfrying. ${ }^{[20]}$ However, some authors have shown the important effect of post-frying cooling for the oil impregnation in partially fry-dried materials ${ }^{[63]}$ and conclusively showed that for those cases, the oil does not penetrate the product during frying, but it is taken up when the sample is removed from the fryer due to adhesion of oil to the surface of the product. ${ }^{[64]}$

Fourth Period: Fry-Drying of Sewage Sludge as a Boiling in a Porous Media. Finally, for the fry-drying times longer than $720 \mathrm{~s}$, the partially fry-dried sludge is formed by a complex solid material formed by voids and holes, which seems to be partially interconnected to each other.

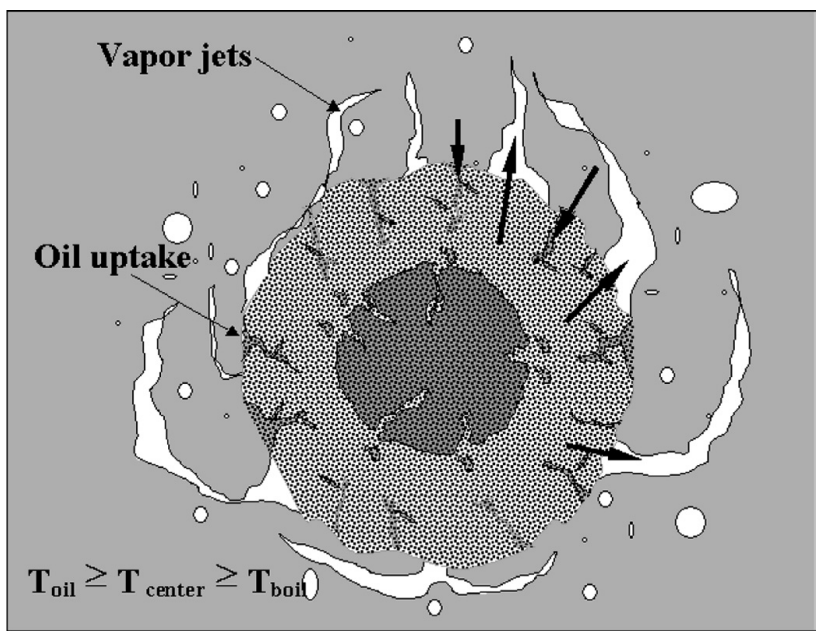

FIG. 19. Schematized regions within the cross section of a sewage sludge sample during period 3 of fry-drying.

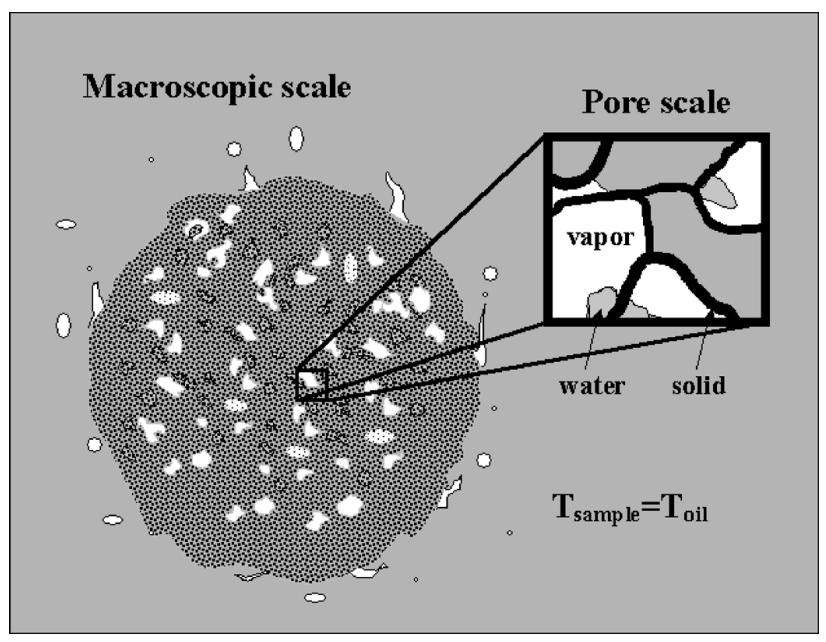

FIG. 20. Schematized regions within the cross section of a sewage sludge sample during period 4 of fry-drying.

The solid matrix, which is relatively easy to break although it offers a certain cohesion, may contain, at a very small scale, gas (vapor) and liquid (oil and water) on $i^{[21]}$ (see Fig. 20). In addition, it was observed at this stage, that the remaining capillary and interstitial water is removed at a decreasing drying rate without any temperature profile within the sample and at some tens of degrees Celsius higher than $T_{\text {boil }}$ (see Fig. 12). All these results, suggest a configuration for the phase change in a porous media. ${ }^{[59,60]}$

Such a process occurs in the confines of the pore space (at a scale of $\mu \mathrm{m})^{[60]}$ and it is driven by the application of a super saturation at the external boundaries of the porous medium, where the phase equilibrium and drying kinetics are determined by the transport of heat and mass within the pore structure and also by the intermolecular forces between the fluids and the pore surface. ${ }^{[59]}$

Indeed, porous media can be seen at various scales, from rough pore surfaces through isolated pores, pore networks to the macroscopic continuum. Consequently, while the nucleation and phase equilibrium are affected mainly by the surface roughness and the intermolecular interactions at microscale, or by capillarity at a intermediate or mesoscale, the macroscale heterogeneity controls the large scale behavior. ${ }^{[59]}$

Although there is a consensus about the physical mechanisms involved in this process (i.e., capillarity, molecular diffusion, pressure driven flow,...), there is still a number of unknowns when analyzing such process where the main scientific difficulty is to explain the linkage between the micro- and macroscales. ${ }^{[60]}$

Such an approach was applied by $\mathrm{Ni}$ and Datta ${ }^{[21]}$ to validate the experimental data obtained during the 
fry-drying process of thick samples of potato (tubers samples of $25 \mathrm{~mm}$ in diameter). Although the model validates only partially the temporal results in a macroscopic scale, namely drying and heating curves, it provides a good insight on the non-negligible effect of the local transport mechanisms such as internal pressure increase and water capillary flux, which plays a more important role for the long frying times.

\section{Discussion about the Differences Between the Fry-Drying} of Sewage Sludge and the Food Frying Processes

In the fry-drying of sewage sludge experiments, as well as all the fry-drying operations, there are two kinds of resistances for the heat transfer and for the corresponding mass transport. They are referred with respect to the sample itself to give one external resistance, which is formed between the oil bath and the surface of the sample and other internal resistance, which is given by the half thickness of the sample (see Fig. 14).

Studies on immersion frying of food (i.e., french fries, potato chips, tortilla chips, and so on) consider that almost all water removal is fully controlled by heat transfer similar to that in a moving boundary problem..$^{[15,19,36]}$ In fact, due to the partial drying of the thick samples (i.e., french fries) or to the small thickness of the fully dried samples (i.e., chips), the transport-related problems are small and often neglected. ${ }^{[56,57,65]}$ Consequently, food frying is usually treated as a Stefan problem ${ }^{[58]}$ where the oil uptake is negligible, ${ }^{[17,18]}$ and the main internal resistance is provided by the low thermal conductivity of the crust (i.e., $\left.k_{\text {crust }} \leq 100 \times 10^{-3} \mathrm{~W} \cdot \mathrm{m}^{-1} \cdot \mathrm{K}^{-1}\right) \cdot{ }^{[2]}$ The insulating layer is described as an oil-free porous matrix where all the holes, voids, and capillary networks are occupied by water vapor. $^{[47]}$

Such studies made on immersion frying process of typical fried foods identify three stages depending on the evolution of the temperature at the center of the sample $T_{\text {center }}{ }^{[2]}$ :

Stage 1 An initial heating of the sample with a simultaneous settlement of a temperature profile in the inner layers of the sample with $T_{\text {center }}<T_{\text {boil }}$, accompanied by intensive boiling at the surface of the sample $T_{\text {surface }} \approx T_{\text {boil }}$.

Stage 2 Displacement of the vaporization front from the surface to the center of the sample (i.e., $T_{\text {center }} \approx T_{\text {boil }}$ ) producing an internal boiling, at the end of which up to $95 \%$ of the initial free and capillary water is removed.

Stage 3 Increase of the sample temperature (i.e., $T_{\text {center }} \rightarrow$ $\left.T_{\text {oil }}\right)$ accompanied by decreasing drying rates.

Concerning our study, within the first $400 \mathrm{~s}$ of the experiment, the crust and core regions were clearly observed within the sample (see Fig. 13). This suggested that, for instance, the process was driven mostly by heat transfer mechanisms and limited by the crust formation, similarly to the smaller food fried samples.

However, it was observed that when $T_{\text {center }} \geq T_{\text {boil }}$ the sample still has $2.24 \mathrm{~kg}$ water $\cdot \mathrm{kg}^{-1}$ total dry solids (i.e., $39 \%$ of the initial moisture content of the sample). According to the stages previously described for the food frying, all the water that remains in the sample at that moment should be considered as hygroscopic moisture in equilibrium with the heated oil. However, in our case the sample continues to dry at such high temperatures (see Fig. 17).

The fact that almost two fifths of the initial free and capillary moisture is removed only during the so-called hygroscopic period at some tens above $T_{\text {boil }}$ suggested that other phenomena fundamentally different to heat transfer control the last part of the process. ${ }^{[21]}$ The described transport mechanisms occurring while the phase change in a porous media ${ }^{[59]}$ (i.e., capillary, molecular diffusion, and pressure driven flow), which are spatially varying, and functions of the porous structure seem to be the probable limiting mechanisms at this part of the operation. Due to their complex nature and relative small influence on most typical applications of immersion frying of foods, they are seldom included for heat and mass transfer analysis. ${ }^{[21]}$

\section{Applying the Immersion Frying for the Thermal Drying of Sewage Sludge}

Effect of Some Selected Operational Conditions on the Drying Curves

Once some insights on the mechanisms involved in the fry-drying of sewage sludge are given, it is now necessary to evaluate some selected operational parameters to adequate the immersion frying operation to the thermal drying of sewage sludge. Concerning the external parameters, only the frying oil temperature was taken into account. In fact, other external conditions such stirring speed $^{[37,66]}$ or frying oil quality or type $\mathrm{p}^{[32,33]}$ have shown a slight influence in the frying kinetics compared to the oil temperature. In addition, the initial moisture content and the size of the samples of the sludge were examined as internal parameters.

Oil Temperature. In order to evaluate the effect of the external conditions on the fry-drying kinetics, four temperatures were studied, namely 120, 140, 160, and $180^{\circ} \mathrm{C}$.

As shown in Fig. 21, the first principal effect of the oil temperature $T_{\text {oil }}$ concerns the duration of the process. As expected, the higher frying temperature the shorter drying time. However, the decrease of time is not proportional to the increase of $T_{\text {oil }}$. It seems that there should be a critical temperature, located close to $T_{\text {oil }}=160^{\circ} \mathrm{C}$, beyond 


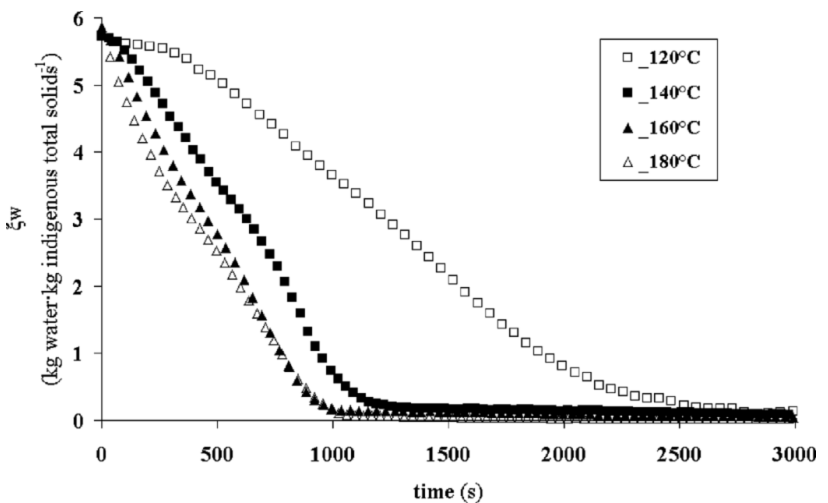

FIG. 21. Effect of oil temperature on the drying curves.

which no significant reduction on the frying time is produced.

In fact, the effect of $T_{\text {oil }}$ seems to be limited by the presence of three different critical moisture contents that appear regardless of the frying temperature. These points can be approximately determined from the corresponding Krischer curves (Fig. 22). During the first period, the film of vapor should cover almost instantaneously the product when fry-drying is achieved at $180^{\circ} \mathrm{C}$, as it is evidenced by a falling drying rate period occurring immediately after the beginning of the experiment (Fig. 22). As a result, when the fry-drying is achieved at higher temperatures, the sample surface is dried more rapidly and a thicker film of vapor is produced. This initial surface boiling has some consequences concerning the subsequent periods. Table 5 shows that the calculated values of $k_{\text {app }}$ and $h_{0}$ decrease inversely with the frying temperature, suggesting that the $h_{0}$ values should be directly affected by the size of the blanket of vapor formed around the sample. Furthermore, the rapid removal of the capillary water at high temperatures avoids the heat-pipe effect and the corresponding enhancement of $k_{\text {app }}$ during this period.

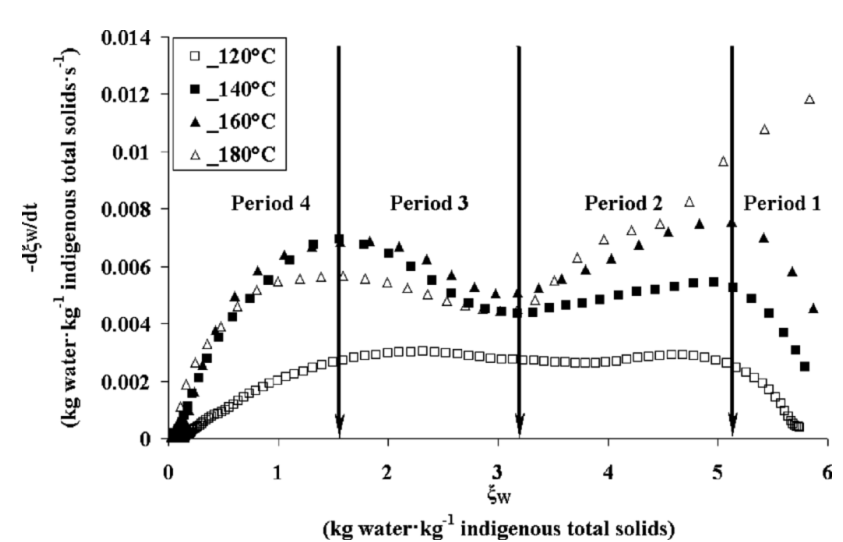

FIG. 22. Effect of oil temperature on the Krischer curve.
TABLE 5

Effect of the frying temperature on the internal and external resistances during the second period of fry-drying of sewage sludge

\begin{tabular}{lcccc}
\hline$T_{\text {oil }}\left({ }^{\circ} \mathrm{C}\right)$ & 120 & 140 & 160 & 180 \\
\hline$k_{\text {app }}\left(\mathrm{W} \cdot \mathrm{m}^{-1} \cdot \mathrm{K}^{-1}\right)$ & 6.1 & 3.3 & 2.2 & 2.0 \\
$\mathrm{~h}_{0}\left(\mathrm{~W} \cdot \mathrm{m}^{-2} \cdot \mathrm{K}^{-1}\right)$ & 370 & 300 & 270 & 220 \\
\hline
\end{tabular}

To sum up, experimental results provide information to consider that frying temperatures have an effect on the kinetics of the fry-drying only for a range of temperature (i.e., 120 to $160^{\circ} \mathrm{C}$ ); beyond this limit, further increases on $T_{\text {oil }}$ do not significantly improve the fry-drying kinetics. Consequently, the optimal range of temperature for the fry-drying of sewage is fixed between 140 and $160^{\circ} \mathrm{C}$.

Sewage Sludge Initial Moisture Content. Figures 23a and $\mathrm{b}$ present the typical fry-drying curves at $160^{\circ} \mathrm{C}$ of two 25-mm-diameter samples having different initial moisture contents after mechanical dewatering (i.e., $\xi_{W}^{t}{ }^{0}=4.8$ and $5.6 \mathrm{~kg}$ water $\cdot \mathrm{kg}^{-1}$ indigenous total solids).

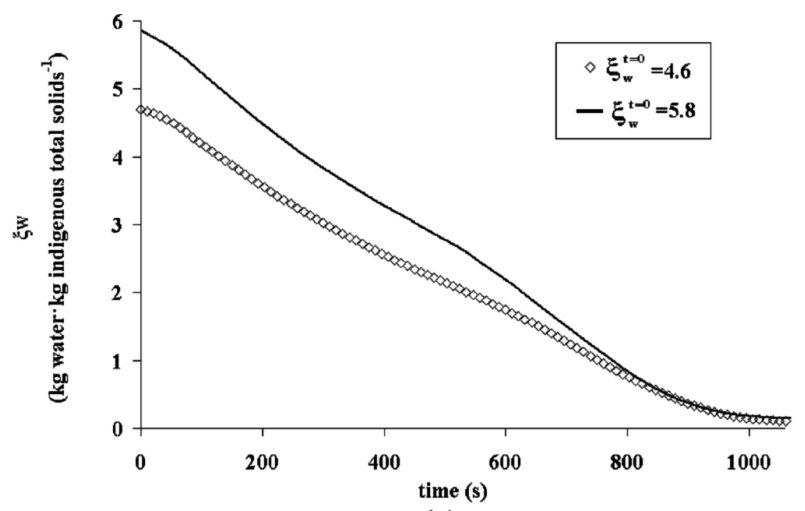

(a)

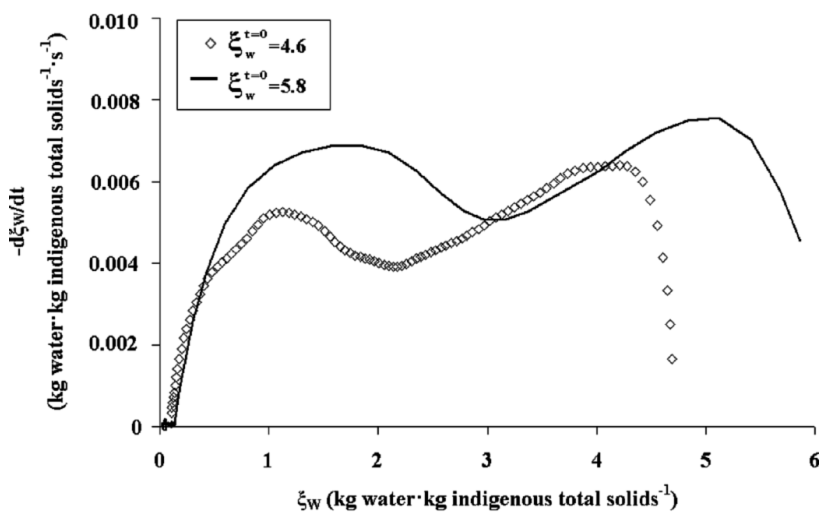

(b)

FIG. 23. Effect of sludge initial moisture content on fry-drying. 
Total fry-drying times are practically the same in both cases (see Fig. 23a). In fact, fry-drying is a self-regulating process where the relative duration and the intensity of the three first periods, namely, heating, boiling front, and oil impregnation, are determined by the competition between the heat transfer and transport mechanisms. Consequently, the moister sample dries more rapidly during the three first periods (see Fig. 23b), and at the end, both samples dry similarly.

Another issue is that the critical moisture at the end of the second period, resulting from the crust formation, is dependent on the initial moisture content of the sample. Thus, while there is still $3.0 \mathrm{~kg}$ water $\cdot \mathrm{kg}^{-1}$ indigenous total solids for the moister sample, there is only $2.0 \mathrm{~kg}$ water $\cdot \mathrm{kg}^{-1}$ indigenous total solids for the drier sludge (see Fig. 23b).

Consequently, it can be said that under the studied conditions the initial moisture content does not have any influence on the duration of the whole process, but only on the relative length and drying intensity of the three first periods, namely, heating, boiling front, and oil impregnation. Thus, the variations observed between one mechanically dewatering degree to other does not have a sensible repercussion on the fry-drying kinetics.

Diameter of the Sample. The effect of the diameter of the samples was analyzed using Figs. 24a and b. As expected, fry-drying time decreases with the reduction of the sample diameter (see Fig. 24a). In fact, a reduction of the diameter implies an increase in the ratio formed by the surface of exchange with the heated oil and the volume of the sample [see Eq. (18)].

$$
\frac{A_{\text {exchange }}}{V_{\text {sample }}}=\frac{4}{D}
$$

This gives a ratio of $270 \mathrm{~m}^{2} \cdot \mathrm{m}^{-3}$ for the smallest sample, whereas it is only $160 \mathrm{~m}^{2} \cdot \mathrm{m}^{-3}$ for the thickest one. This explains the highest drying rates performed with the smallest sample, which almost doubles those of the thickest cylinders at the beginning of the experiment (see Fig. 24b).

Another important advantage of reducing the size of the sample is to shorten the distance for the heat and the mass fluxes involved in the process. ${ }^{[21,35,48]}$ As noted before, for the thick samples these countercurrent fluxes produce a transitional period where transport and heat transfer mechanisms are concurrent. This can be observed easily in Fig. $24 \mathrm{~b}$ for the sample having a diameter of $25 \mathrm{~mm}$, where the drying rate increases suddenly after a falling drying rate period. In contrast, transitional period becomes less straightforwardly observed for the smaller samples (see Fig. 24b).

Finally, the rapidness of the hygroscopic moisture removal does not seem to be dependent on the sample geometry (see Fig. 24b).

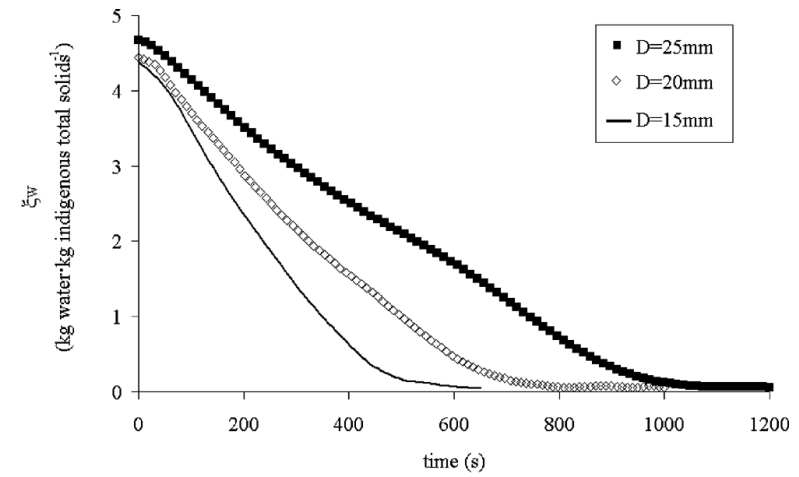

(a)

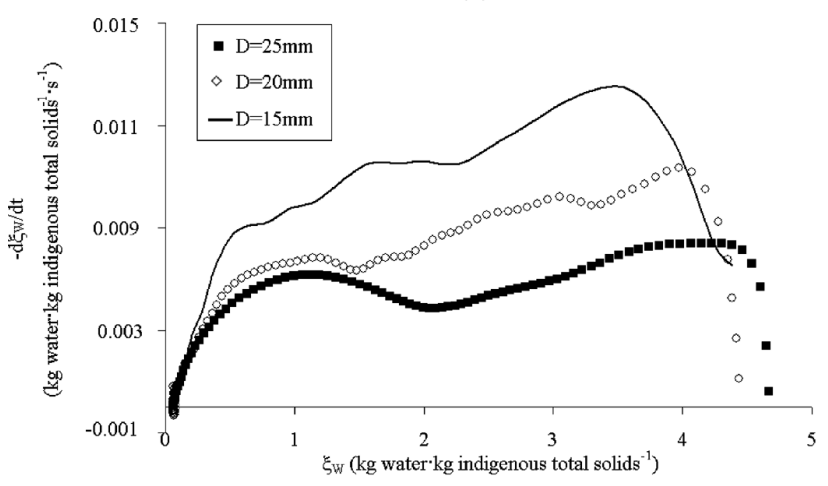

(b)

FIG. 24. Effect of diameter of the sample on fry-drying.

Concerning the diameter of the sample, it can be concluded that the fry-drying will be faster for samples with smaller diameter. Consequently, the optimal diameter of the sample will be limited rather by the technological issues, which concern the rheology of the sewage sludge and at the final disposal of the produced fried sludge.

\section{Fry-Drying of Sewage Sludge, as an Intensive Process}

According to Tsouris and Porcelli, ${ }^{[67]}$ process intensification refers to technologies that replace large, expensive, and energy-consuming equipment or processes with the ones that are smaller, less costly, and more efficient, or that combine multiple operations into fewer devices (or a single apparatus). The following sections will examine how the immersion frying process provides efficacy and multifunctionality for the thermal drying of sewage sludge.

Efficiency of the Operation. A process is more efficient depending on its ability to produce a desired effect. The thermal drying of the sewage sludge is an effect that can be conventionally carried out by three main types of a process depending on the heat transfer $\operatorname{mode}^{[7]}$ :

- In direct dryers, also called convective dryers, the hot gases from the combustion of oil, natural 
TABLE 6

Synthesis of the identified limiting mechanisms for the different types of drying

\begin{tabular}{llcl}
\hline Type of dryer & \multicolumn{1}{c}{ Limiting mechanisms } & Thermal resistance $\left(\mathrm{m}^{2} \cdot \mathrm{K}^{-\mathrm{W}^{-1}}\right)$ & \multicolumn{1}{c}{ Reference } \\
\hline Belt dryer & Convection (fluid-to-bed) & $13 \times 10^{-2}$ & Léonard $^{[82]}$ \\
Spouted-bed dryer & Convection (wall-to-bed) & $0.82 \times 10^{-2}$ & Freitas and Freire $^{[83]}$ \\
Paddle dryer & Contact (wall-to-particle) & $4 \times 10^{-3}$ & Arlabosse $^{[68]}$ \\
Thin-layer dryer & Heating inertia in the wall & $0.55 \times 10^{-4}$ & Carrère-Gée $^{[71]}$ \\
& Contact (wall-to-particle) & $\left(\xi_{W}>1 \mathrm{~kg} \cdot \mathrm{kg}^{-1}\right) 3 \times 10^{-3}$ & \\
& & $\left(\xi_{W}<1 \mathrm{~kg} \cdot \mathrm{kg}^{-1}\right)$ & \\
\hline
\end{tabular}

gas, or the dried sludge itself are mixed with the dewatered cake in the dryer and transport the sludge through the dryer evaporating the water off while in transit. Some examples of this type are the drums, belt, and fluidized bed dryers. ${ }^{[6,68]}$

- In indirect dryers, also called conductive dryers, the heat transfer occurs through the solid barrier. The heat carrying medium, which can be hot gas or thermal oil, is in a separate stream to the vapor. Thus, water is removed by boiling and the resulting vapors are exhausted away from the dryer by a carrying gas, whose flow is low compared to those involved in convective dryers. Some examples of this type are the discs, paddles, or thin-layer dryers. ${ }^{[6,68]}$

- A third type of dryer is a combination of both the above systems using both conduction and convection to remove the water. An example is the spouted-bed dryer. ${ }^{[6]}$

Each category has its advantages and disadvantages when considering their efficiency for the thermal drying of sewage sludge. Ressent ${ }^{[6]}$ explains that on the one hand, due to the absence of mechanical devices or frictional parts, the drying train for direct dryers is generally much simpler and has an easier maintenance than indirect dryers but this advantage is sometimes overwhelmed by the sophisticated emission management system that is required to treat the large amounts of gases involved in the direct drying. On the other hand, the author argues that, due to the mechanisms involved in heat and mass transfers, indirect dryers are more intensive than direct dryers.

Thus, the fry-drying should be considered as a combined or mixed drying because it adapts some of the advantages of direct and indirect dryers. First, heat is transferred by a direct contact between the heated oil and the wet sludge. This issue involves simplicity in the dryer design. However, in the fry-drying, the water is removed by boiling as in indirect dryers. As noted in the previous sections, this suggests high drying rates and a consequent reduction of the amount of exhaust vapors, which considerably limits the problems related to effluents management.
In order to locate the technical efficiency of the frydrying among the other conventional dryers, a good practice is to compare the relative limiting thermal resistance referred to as the heating surface ${ }^{[68]}$ (i.e., $\mathrm{m}^{2} \cdot \mathrm{K} \cdot \mathrm{W}^{-1}$ ). Table 6 gives a comparative synthesis of some selected types of dryers, listing them from the top to the bottom according to the decreasing value of their limiting resistances. Thus, convective dryers have a limiting thermal resistance, which is higher by one order of magnitude than that corresponding to the contact dryers. The overall resistances found for the fry-drying (Fig. 15) can be referred to as the heating sample surface (i.e., the initial sample surface, $A_{\text {heating }}=1.1 \times 10^{-1} \mathrm{~m}^{2}$ ). The results give an overall resistance between 3.0 and $4.4 \times 10^{-3} \mathrm{~m}^{2} \cdot \mathrm{K} \cdot \mathrm{W}^{-1}$ during periods 1 and 2 and 4.5 and $3.4 \times 10^{-3} \mathrm{~m}^{2} \cdot \mathrm{K} \cdot \mathrm{W}^{-1}$ for the third period. As expected, those values locate the fry-drying above all the convective dryers and close to the agitated dryers (see Table 6). Although the thin-layer dryers are more intensive, the simplicity as well as the compactness of the fry-drying process (about $11 \mathrm{~m}^{2} \cdot \mathrm{m}^{3[70]}$ versus $15 \mathrm{~m}^{2} \cdot \mathrm{m}^{3}$ for the thin-layer drying ${ }^{[71]}$ ) makes it a good compromise between simplicity and efficiency. This is confirmed by the economic assessment of a simulated fry-drying process operating in a commercial scale ${ }^{[72]}$ (i.e., processing $1 \mathrm{ton} \cdot \mathrm{h}^{-1}$ of dry solids). This study estimated a lower fixed capital costs of a fry-drying facility than those reported for conventional dryers and similar with a similar operating cost.

Multi-Function of the Operation. As stated before, besides its efficiency, an intensified process may provide multi-functionality. This means that several transformations required to get the final product must take place in the fewer number of stages. In that concern, frydrying offers a good performance when the sewage sludge combustion is preferred as final disposal route, ${ }^{[73]}$ due to the drying and oil impregnation processes that occur simultaneously.

Since the lower heating value $(L H V)$ of the sewage sludge ${ }^{[74}$ increases due to water removal and oil uptake during fry-drying, this process can be seen as an operation of formulation. Consequently, if the final function of the 
fry-dried sludge is to be disposed by incineration, it is possible to prepare an auto-thermal sludge providing important advantages both from economic ${ }^{[70]}$ and environmental ${ }^{[75]}$ points of view. In contrast, if the aim is to produce a fuel, a maximum drying and oil impregnation should be performed. In fact, measurements of the final fry dried sludge $L H V^{[76]}$ show that depending on the frying conditions it is possible to have a solid fuel having an $L H V$ ranging between 18 and $24 \mathrm{MJ} \cdot \mathrm{kg}^{-1}$ of fry-dried sludge, which involves an increase of 50 to $70 \%$ in the $L H V$ reported for the same air-dried sludge. Indeed, the $L H V s$ of the fry-dried sludge can be compared to those of coal or wood. ${ }^{[74]}$

In addition, fry-drying offers the improvement of another characteristic required in the final product: the size of the particle. Indeed, it seems that in the final fry-dried sludge, the dry solids are coated with an oily layer (see Fig. 8c), producing agglomerated grains whose size may reach some tens of millimeters. This is a key issue, since the small particle size of the dried sludge is a main concern not only for sludge processing but also when handling and transporting the dried material. Actually, the inhalation of tiny grains (i.e., particle size between 7 and $20 \mu \mathrm{m}$ ) is an important sanitary risk, as in indirect dryers, like paddle dryers, can produce a final solid with a particle size distribution of $95 \%<2 \mathrm{~mm}^{[77]}$ Furthermore, although the average particle size of convective dryers is larger due to the absence of frictional parts (i.e., $50 \%<2 \mathrm{~mm}$ ), the existence of large amounts of hot air that can be mixed with fine organic powders presents a real risk of explosion in most of the facilities of convective drying. ${ }^{[6]}$

Due to the temperatures and residence times to which the sludge is submitted, it can be argued that fry-drying process may allow produce a hygienic final fry-dried sludge. ${ }^{[78]}$

\section{SUMMARY}

Application of frying for the sewage sludge processing was investigated in this article. Tests were made using a digested municipal sewage sludge and recycled cooking oils ( $\mathrm{RCO})$.

An experimental setup was developed in order to continuously obtain mass and temperature data to analyze the heat and mass transfers during the fry-drying process. Image data complemented those measurements.

According to the reference treatment, the following scenario comprising four periods of fry-drying was proposed:

1. An initial heating period (approximately $150 \mathrm{~s}$ over which $17 \%$ of $\xi_{W}^{t}$ is removed). The sample surface is heated from its initial temperature to an elevated water boiling point (i.e., $102104^{\circ} \mathrm{C}$ ) accompanied by a nucleate boiling of the surface water.

2. A second boiling front period (between $150<t<400 \mathrm{~s}$ where $28 \%$ of $\xi_{W}^{t}$ is removed). A film of vapor covers the sample and moves inwards, developing two regions in the product: a crust and a core.

3. A third period involves the oil penetration into the product (between $400<t<720$ seconds over which $31 \%$ of $\xi_{W}^{t}{ }^{0}$ is removed). The oil uptake promotes a very intense internal evaporation that plays an important role in transport mechanisms (i.e., capillarity, pressure driven flows, intermolecular forces,...) in the fry-drying kinetics. The core and crust regions developed in the second period are no longer differentiated.

4. A fourth period removes about $22 \%$ of $\xi_{W}^{t}{ }^{0}$ for $t>720 \mathrm{~s}$ when the temperature gradient is no longer observed. This period is associated to a change phase in a porous media, where the liquid water vapor equilibrium is obtained at a microscale at a temperature some tens of degrees higher than the pure water boiling point.

The values of the measured apparent thermal conductivity $\left(k_{\text {app }}\right)$ of the crust were higher than those reported for the typical fried foods. It was proposed that this enhancement of $k_{\text {app }}$ may be due to successive capillary vaporization-condensation processes taking place in a microscale in the crust, similar to what occurs in the micro-heat pipes.

Furthermore, selected fry-drying conditions were evaluated (i.e., oil temperature, initial moisture content, and diameter of the sample) in order to understand their influence on the fry-drying kinetics. Experimental results provide information to consider that fry-drying is affected only for a range of temperature (i.e., 120 to $160^{\circ} \mathrm{C}$ ); beyond this limit heat transfer is mainly controlled by internal conduction phenomena. Consequently, the optimal frying temperature is comprised between 140 and $160^{\circ} \mathrm{C}$. Moreover, it was observed that a reduction from 5.8 to $4.7 \mathrm{~kg}$ water $\cdot \mathrm{kg}^{-1}$ of indigenous total dry solids does not significantly reduce the fry-drying time. In fact, the transition between the different fry-drying periods occurred at different critical moisture contents. Finally, fry-drying of sewage sludge is sensitive to the thickness of the sample during the first part of the process (i.e., periods 1 to 3 ). However, the bound moisture is not sensitive to the geometric conditions. According to the results, it is worthy to fry-dry the sludge using the technologically smallest sample diameter.

It was also found that the limiting thermal resistance was highly influenced by the formation of a film of vapor covering the sample during the second period. The order of magnitude of the overall thermal resistance was estimated at about $3.04 .4 \times 10^{-3} \mathrm{~m}^{2} \cdot \mathrm{K} \cdot \mathrm{W}^{-1}$ in period 2 , and then it decreased to $3.4 \times 10^{-3} \mathrm{~m}^{2} \cdot \mathrm{K} \cdot \mathrm{W}^{-1}$ during the 
third period. In terms of efficiency, this locates the fry-drying above the convective dryers and close to the agitated indirect dryers. Although there exist other drying techniques, such as thin film drying, that offer a more efficient heat transfer, the absence of frictional and mechanical devices as well as the high compactness of the fry-drying, offer a good compromise between efficacy and simplicity.

It was shown that fry-drying is a multi-functional operation that dries, formulates, and consolidates the product. All these three functions are important in the entire system for the disposal of sewage sludge.

Some limitations to the application of the technique are also apparent. First, the oil impregnation does not allow agricultural land spreading. Thus, the only final disposal method for fried sludge is incineration, and the frying oils must be available. However, these constraints are not very limiting in the European context. On the one hand, most countries are moving to decrease land filling and land spreading of sewage sludge, with the inevitable increase of the use of incineration as a disposal method. ${ }^{[79,80]}$ In fact, new incineration technologies as well as pyrolysis and gasification processes applied to the sewage sludge ${ }^{[73]}$ belong to the group of Energy from Waste Incineration $($ EfWI $),{ }^{[81]}$ which claims its place as natural companion of the practicable recycling in a truly integrated waste management hierarchy. On the other hand, due to the food safety problems in 1999 in Europe, the market for recycled cooking oils especially for animal feed has considerably decreased. Thus, these food industry by-products are becoming available as an oil resource with good chemical and physical stability. Moreover, from a technical point of view, practically any oil can be used as fry-drying oil, besides from the RCO, although some economic and environmental issues should be taken into account. Thus, the high heavy metal content of motor waste oils or the high costs of fresh vegetal oils are important drawbacks that limit their utilization in fry-drying of sewage sludge process. Nevertheless, an interesting alternative to frying oil could be the grease and oils that are skimmed from the top of the tanks during the pre-treatment and primary treatment from a WWTP. Indeed, they offer the convenience of being collected in the same location as the sludge. Nonetheless, a pretreatment to remove the solid matter and moisture that is contained in this waste must be implemented before using them as frying oil. As a consequence, further experimental and economic studies are necessary to determine the feasibility of such material as frying oil.

The analysis presented in this article provides information concerning the physical mechanisms that take place in the fry-drying of sewage sludge as well as discussion about its application to thermal drying of sewage sludge. This information is important for future modeling and larger scale developments of such a process.

\section{NOMENCLATURE}

A Surface area $\left(\mathrm{m}^{2}\right)$

a Constant used in Nusselt number correlation

$b \quad$ Constant used in Nusselt number correlation

$C_{p} \quad$ Specific heat $\left(\mathrm{J} \cdot \mathrm{kg}^{-1} \cdot \mathrm{K}^{-1}\right)$

$D \quad$ Diameter of the sample (m)

$g \quad$ Acceleration due to gravity $\left(\mathrm{m} \cdot \mathrm{s}^{-2}\right)$

$\Delta H \quad$ Latent heat of vaporization $\left(\mathrm{J} \cdot \mathrm{kg}^{-1}\right)$

$h_{0} \quad$ Convective heat transfer coefficient during

boiling $\left(\mathrm{W} \cdot \mathrm{m}^{-2} \cdot \mathrm{K}^{-1}\right)$

$h_{f c} \quad$ Convective heat transfer coefficient during

free convection $\left(\mathrm{W} \cdot \mathrm{m}^{-2} \cdot \mathrm{K}^{-1}\right)$

Thermal conductivity $\left(\mathrm{W} \cdot \mathrm{m}^{-1} \cdot \mathrm{K}^{-1}\right)$

Length of the sample (m)

Mass $(\mathrm{kg})$

Mass flux $\left(\mathrm{kg} \cdot \mathrm{m}^{-2} \cdot \mathrm{s}^{-1}\right)$

Initial radius of the sample $(\mathrm{m})$

Moving front radius (m)

Thermal resistance $\left(\mathrm{K} \cdot \mathrm{W}^{-1}\right)$

Temperature (K)

Time (s)

\section{Greek Letters}

$\alpha \quad$ Mass ratio between the liquid and vapor losses

$\beta \quad$ Coefficient of volumetric thermal expansion

$\left(\mathrm{K}^{-1}\right)$

$\varepsilon \quad$ Thermal diffusivity $\left(\mathrm{m}^{2} \cdot \mathrm{s}^{-1}\right)$

$\nu \quad$ Kinematic viscosity $\left(\mathrm{m}^{2} \cdot \mathrm{s}^{-1}\right)$

$\xi \quad$ Content

\section{Dimensionless Numbers}

$\mathrm{Nu} \quad$ Nusselt number

$\mathrm{Ra} \quad$ Rayleigh number

\section{Subscripts/Superscripts}

boil Water boiling point

container Sample container

oil Frying oil

RCO Impregnated oil

sample Partially fry-dried sludge

support Metallic support

surface Condition at the external surface of the sample

\section{TFS Total fixed solids}

TS Total solids

TVS Total volatile solids

$t=0 \quad$ Initial conditions

$t=i \quad$ Conditions at drying time $i$

$t=n \quad$ Final conditions

W Moisture

$W$ cont Moisture calculated continuously considering the liquid and vapor water losses

$W$ disc Moisture calculated discontinuously

$W$ (in) Liquid water losses 


\section{REFERENCES}

1. Vermeersch, G.; Raoult-Wack, A.L.; Trystram, G. Understanding the frying process: Product quality. OCL, Oléagineux Corps Gras Lipides 1998, 5 (1), 2829 (in French).

2. Vitrac, O. Experimental Characterization and Modeling of the Frying Operation; Ph.D. Thesis. Ecole Nationale Supérieure des Industries Agricoles et Alimenatires: Paris, France, 2000 (in French).

3. Arlabosse, P. Study on Thermal Drying Processes of Municipal and Industrial Sewage Sludges; Report no. 99-0217/1A; Ecole des Mines d'Albi Carmaux \& Association RE.CO.R.D.: Albi, France, 2001 (in French).

4. Grüter, H.; Matter, M.; Oehlmann, K.H.; Hicks, M.D. Drying of sewage sludge. An important step in waste disposal. Water Science and Technology 1990, 22 (12), 5763.

5. Vaxelaire, J.; Bongiovanni, J.M.; Mousques, P.; Puiggali, J.R. Thermal drying of residual sludge. Water Research 2000, 34 (17), 43184323.

6. Ressent, S. State of the Art in Thermal Drying of Municipal and Industrial Sewage Sludge; Agence de l'eau Seine-Normandie: Paris, France, 1998 (in French).

7. Chen, G.; Yue, P.L.; Mujumdar, A.S. Sludge dewatering and drying. Drying Technology 2002, 20 (4 5), 883916.

8. Kudra, T. Sticky region in drying Definitions and identification. Drying Technology 2003, 21 (8), 14571469.

9. Lowe, P. Developments in the thermal drying of sewage sludge. Journal of the Chartered Institution of Water and Environmental Management 1995, 9 (3), 306.

10. Pires da Silva, D. Study of Sewage Sludge Drying Using Immersion Frying; Ph.D. Thesis. Universidade Estadual de Campinas: Campinas, SP, Brazil, 2003 (in Portuguese).

11. Peregrina, C.; Arlabosse, P.; Lecomte, D. Fry-drying of sewage sludge: An alternative for the disposal of recycled food oils. The 9th International Congress on Engineering and Food ICEF09; 711 March; Montpellier, France, 2004; 154159.

12. Peregrina, C.; Arlabosse, P.; Lecomte, D. Thermal efficiency in sewage sludge fry drying. In Proceedings of the 14th International Drying Symposium IDS; São Paulo, Brazil, 2004; 972978.

13. Boatella-Riera, J.; Codony, R.; Rafecas, M.; Guardioal, F. Recycled Cooking Oils: Assessments of Risk for Public Health; European Parliament: Luxembourg, 2000.

14. Mauvieux, P.; Madeline, Y.; Gabarda-Oliva, D.; Fondin, P.; Cholin, B.; Picard, J.M. Greasy Wastewater Treatment: Which Are the Solutions and Their Costs?; Pollutec 2001 Paris, France, 2001 (in French).

15. Mittelman, A.; Mizrahi, S.; Berk, Z. Heat and mass transfer in frying. In Engineering and Food; McKenna, B.M., Ed.; Elsevier Applied Science Publishers, 1984; 109116

16. Gamble, M.H.; Rice, P.; Selman, J.D. Relationships between oil uptake and moisture loss during frying potato slices from c.v. Record U.K. tubers. International Journal of Food Science and Technology 1987, 22, 233241.

17. Farkas, B.E.; Singh, R.P.; Rumsey, T.R. Modeling heat and mass transfer in immersion frying. I, Model development. Journal of Food Engineering 1996, 29 (2), 211226.

18. Farkas, B.E.; Singh, R.P.; Rumsey, T.R. Modeling heat and mass transfer in immersion frying. II, Model solution and verification. Journal of Food Engineering 1996, 29 (2), 227248.

19. Singh, R.P. Heat and mass transfer in foods during deep-fat frying. Food Technology 1995, 49 (4), 134137.

20. Moreira, R.; Castell-Perez, M.; Barrufet, M. Deep-Fat Frying: Fundamentals and Applications. Food Engineering; Aspen Publications: Gaithersburg, MD, 1999.

21. Ni, H.; Datta, K. Moisture, oil and energy transport during deep-fat frying of food materials. Trans IChemE 1999, 77 (C), 194204.
22. Saguy, S.; Pinthus, E.J. Oil uptake during deep-fat frying: Factors and mechanism. Food Technology 1995, 49 (4), 142 145, 152.

23. Saguy, S.; Ufheil, G.; Livings, S. Oil uptake in deep-fat frying: Review. OCL, Oléagineux Corps Gras Lipides 1998, 5 (1), 3035.

24. McGill, E.A. The chemistry of frying. Baker's Digest 1980, 54 (3), 3842.

25. Graille, J. Chemical reactions induced by the frying. OCL, Oléagineux Corps Gras Lipides 1998, 5 (1), 3640 (in French).

26. Dobarganes, C. Formation and analysis of high molecular weight compounds in frying fats and oils. OCL, Oléagineux Corps Gras Lipides 1998, 5 (1), 4147.

27. Blumenthal, M. A new look at the chemistry and physics of deep-fat frying. Food Technology 1991, 45 (2), 68 71, 94.

28. Chavez, S. Agitated Conductive Drying Process of Municipal Sewage Sludge: Effect of the Type of Sludge and the Operating Conditions upon the Drying Kinetics and the Characteristics of the Dried Sludge and the Exhaust Vapors; Ph.D. Thesis, Université de Perpignan: Perpignan, France, 2004 (in French)

29. Arlabosse, P.; Chavez, S. Characterization of some sewage sludge properties essential for the design and management of thermal processes. Environmental Technology 2005, Submitted.

30. Huyard, A.; Ducray, F.; Patria, L. Sewage Sludge: Respect of French Regulation and Impact of the Future European Directive Project; CNISF:AGHTM symposium Pollutec, 28 November 2002, Lyon, France.

31. Sud-Recupération. Treatment and Disposal of Recycled Cooking Oils; available at www.sudr-recuperation.fr/traitement.html, accessed 15 August 2005 (in French).

32. Miller, K.S.; Singh, R.P.; Farkas, B.E. Viscosity and heat transfer coefficients for canola, corn, plam and soybean oil. Journal of Food Processing and Preservation 1994, 18 (6), 461472.

33. Tseng, Y.; Moreira, R.; Sun, X. Total frying-use time effects on soybean-oil deterioration and on tortilla chip quality. International Journal of Food Science and Technology 1996, 31 (3), 287294.

34. Nawar, W.W. Lipids. In Food Chemistry, 3rd Ed; Marcel Dekker, Inc.: New York, 1996; 254299.

35. Baumann, B.; Escher, F. Mass and heat transfer during deep-fat frying of potato slices 1. Rate of drying and oil uptake. Lebensmittel Wissenschaft und Technologie 1995, 4 (28), 395403.

36. Moreira, R.; Palau, J.; Sun, X. Simultaneous heat and mass transfer during the deep fat frying of tortilla chips. Journal of Food Processing Engineering 1995, 18 (3), 307320.

37. Vitrac, O.; Dufour, D.; Trystram, G.; Raoult-Wack, A.-L. Characterization of heat and mass transfer during deep-fat frying and its effect on cassava chip quality. Journal of Food Engineering 2002, 53 (2), 161176.

38. Kemp, I.C.; Fyhr, B.C.; Laurent, S.; Roques, M.A.; Groenewold, C.E.; Tsotsas, E.; Sereno, A.A.; Bonazzi, C.B.; Bimbenet, J.J.; Kind, M. Methods for processing experimental drying kinetics data. Drying Technology 2001, 19 (1), 1534.

39. Vitrac, O.; Bohuon, P. Internal coupled heat and mass transfer during deep-frying of materials with high water contents: Application to apple chips fried at atmospheric pressure. The 9th International Congress on Engineering and Food-ICEF09; Montpellier, France, 2004; 177182.

40. Degremont. Water Technical Handbook; Tec \& Doc-Lavoisier: Paris, France, 1989 (in French).

41. Aguilera, J.; Gloria, H. Determination of oil in fried potato products by differential scanning calorimetry. Journal of Agricultural and Food Chemistry 1997, 45, 781785 .

42. Canselier, J.P.; Poux, M. Processes of Emulsification Mechanisms of Emulsion Formation; Techniques de l'ingénieur. Ref:J2150 52 (in French). 
43. Peters, D.C. Dynamics of emulsification. In Mixing in the Process Industries, 2nd Ed; Butterworth-Heinemann: Oxford, UK, 1992; 294314.

44. Carey, V.P. Transport effects and dynamic behavior of interfaces. In Liquid-Vapor Phase-Change Phenomena; Series in Chemical and Engineering, Taylor \& Francis: Bristol, PA, 1992; 85126.

45. Melton, S.L.; Jafar, S.; Sykes, D.; Trigiano, M.K. Review of stability measurement for frying oils and fried food flavor. Journal of the American Oil Chemists' Society 1994, 71 (12), 1301.

46. Paddy, J.F.; Russell, D.R. The measurement of the surface tension of pure liquids and solutions. Journal of Colloid Science 1960, 15, 503511.

47. Farkas, B.E.; Hubbard, L.J. Analysis of convective heat transfer during immersion frying. Drying Technology 2000, 18 (6), 12691285

48. Costa, R.M.; Oliveira, F.A.R.; Delaney, O.; Gekas, V. Analysis of the heat transfer coefficient during potato frying. Journal of Food Engineering 1999, 39 (3), 293299.

49. Costa, R.; Oliveira, A.; Delaney, O. Dependency of the heat transfer coefficient on surface boiling during frying of potato slices. In Proceedings of the 11th International Drying Symposium (IDS'98); Halkidiki, Greece, 1998; 11941199.

50. Hubbard, L.J.; Farkas, B.E. Determination of the convective heat transfer coefficient during immersion frying. In Proceedings of the 11th International Drying Symposium (IDS'98); Halkidiki, Greece, 1998; 781788 .

51. Sahin, S.; Sastry, S.K.; Bayindirli, L. The determination of convective heat transfer coefficient during frying. Journal of Food Engineering 1999, 39 (3), 307311.

52. Vitrac, O.; Trystram, G.; Raoult-Wack, A.-L. Continuous measurement of convective heat flux during deep-frying: validation and application to inverse modeling. Journal of Food Engineering 2003, 60 (2), 111124.

53. Pannu, K.S.; Chinnan, M.S. Relating food frying to daily oil abuse. Part I. Determination of surface heat transfer coefficients with metal balls. In Transport Phenomena in Food Processing; CRC Press: Boca Raton, FL, 2003; 399412.

54. Whitaker, S. Fundamental Principles of Heat Transfer; Pergamon Press: New York, 1977.

55. Tong, L.S.; Tang, Y.S. Boiling Heat Transfer and Two-Phase Flow, 2nd Ed.; Series in Chemical and Mechanical Engineering, Taylor and Francis: London, 1997.

56. Farid, M. The moving boundary problems from melting and freezing to drying and frying of food. Chemical Engineering and Processing 2002, 41 (1), 110

57. Farid, M. A unified approach to the heat and mass transfer in melting, solidification, frying and different drying processes. Chemical Engineering Science 2001, 56 (18), 54195427.

58. Stefan, J. Ice development theory: Formation of ice in the Polar seas. Annalen der Physik und Chemie 1891, 42, 269286 (in German).

59. Yortsos, Y.C.; Stubos, A.K. Phase change in porous media. Current Opinion in Colloid \& Interface Science 2001, 6 (3), 208216

60. Topin, F. Boiling in a Porous Material. Seminar on liquid-solid change phase and its applications. Cargèse, France, 2003 (in French).

61. Lallemand, M. Phase Change in Confined Environments. Seminar on liquid-solid change phase and its applications. Cargèse, France, 2003 (in French).

62. Chen, Y.; Moreira, R. Modelling of a batch deep-fat frying process for tortilla chips. Trans IChemE 1997, 75 (Part C), 181190.

63. Moreira, R.; Sun, X.; Chen, Y. Factors affecting oil uptake in tortilla chips in deep-fat frying. Journal of Food Engineering 1997, 31, 485 498.

64. Ufheil, G.; Escher, F. Dynamics of oil uptake during deep-fat frying of potato slices. Lebensmittel Wissenschaft und Technologie 1996, 29,640644
65. Smith, M.C.; Farid, M. A single correlation for the prediction of dehydration time in drying and frying of samples having different geometry and size. Journal of Food Engineering 2004, 63 (3), 265271.

66. Diaz, A.; Totte, A.; Giroux, F.; Reynes, M.; Raoult-Wack, A.L. Deep-fat frying of plantain (Musa paradisiaca L.). I. Characterization of control parameters. Lebensmittel Wissenschaft und Technologie 1996, 29, 489497.

67. Tsouris, C.; Porcelli, J.V. Process intensification Has its time finally come? CEPmagazine 2003, October Issue, pp. 5055

68. Arlabosse, P. Penetration model for contact drying of agitated sewage sludge. Chemical Engineering Transactions 2005, 7 (2), 701706.

69. Brereton, C.; Lim, C. Spouted bed drying of sludge from metals finishing industries wastewater treatment plants. Drying Technology 1993 11 (2), 389399

70. Peregrina, C.; Arlabosse, P.; Lecomte, D.; Rudolph, V. Fry-drying: An intermediate sustainable operation for the co-disposal of sewage sludge and waste food oil. 7th World Congress of Chemical Engineering; Glasgow, Scotland, 1015 July, 2005.

71. Carrère-Gée, C. Indirect Drying of Thin-Film Alumina Sludge by Boiling Application on Drum Drying; Ph.D. Thesis. Université Paul Sabatier: Toulouse, France, 1999 (in French).

72. Peregrina, C.; Rudolph, V.; Lecomte, D.; Arlabosse, P. A new application of immersion frying for the thermal drying of sewage sludge: An economic assessment. Journal of Environmental Management 2006, Submitted.

73. Werther, J.; Ogada, T. Sewage sludge combustion. Progress in Energy and Combustion Science 1999, 25 (1), 55116.

74. Niessen, W.R. Biological wastewater sludge: sludge properties. In Combustion and Incineration Processes: Applications in Environmental Engineering, 2nd Ed; Marcel Dekker, Inc.: Cambridge, MA, 1995; 168169

75. Peregrina, C.; Lecomte, D.; Arlabosse, P.; Rudolph, V. Life cycle assessment (LCA) applied to the design of an innovative drying process for sewage sludge. Process Safety and Environmental Protection 2005 (in press).

76. Pires da Silva, D.; Peregrina, C.; Arlabosse, P.; Lecomte, D.; Pereira, O.; Rudolph, V. Fry-drying of sewage sludge: Preliminary results. 6th Conference on Process Integration, Modeling and Optimization for Energy Saving and Pollution Reduction PRES'03; Hamilton, Ontario, Canada, 2003.

77. Ressent, S. Testing the Efficiency of Thermal Dryers of Municipal and Industrial Sewage Sludges; Report no. 99INDU04; Agence de l'eau Seine-Normandie: Paris, France, 1999, 268 (in French)

78. Bresters, A.R.; Coulomb, I.; Deak, B.; Matter, B.; Saabye, A.; Spinosa, L.; Utvik, A. Sludge Treatment and Disposal: Management Approaches and Experiences; European Environmental Agency \& International Solid Waste Association: Copenhagen, 1997.

79. Christiannsen, K.M. Waste Annual Topic Update 1998. European Environment Agency: Copenhagen, 1999.

80. Munck-Kampmann, B. Waste Annual Topic Update 2000; European Environment Agency: Copenhagen, 2001

81. Porteous, A. Energy from waste incineration A state of the art emissions review with an emphasis on public acceptability. Applied Energy 2001, 70 (2), 157167.

82. Léonard, A. Study of Convective Drying of Wastewater Sludge Texture Follow-Up by X-Ray Microtomography; Ph.D. Thesis. Université de Liège: Liège, Belgium, 2002 (in French).

83. Freitas, L.; Freire, J. Heat transfer in spouted beds. Drying Technology 1993, 11 (2), 303317.

84. Couturier, C.; Berger, S.; Hérault, I.; Meiffren, I. Anaerobic Digestion of Municipal Sewage Sludge: State of the Art; Agence de l'eau AdourGaronne \& Solagro: Toulouse, France, 2001 (in French). 